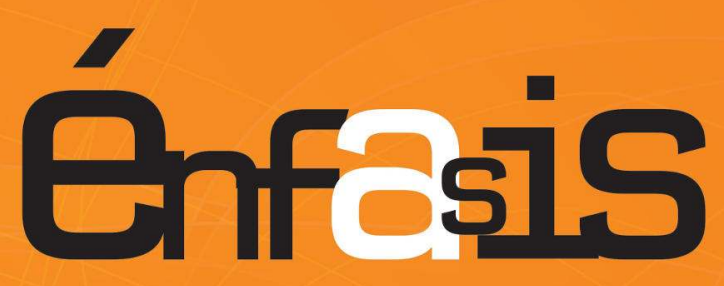

\title{
ENSEÑANDO GEOMETRÍA CON TECNOLOGÍA DIGITAL Una propuesta desde la Teoría de las Situaciones Didácticas
}

Autores Martín Eduardo Acosta Gempeler Jorge Enrique Fiallo Leal

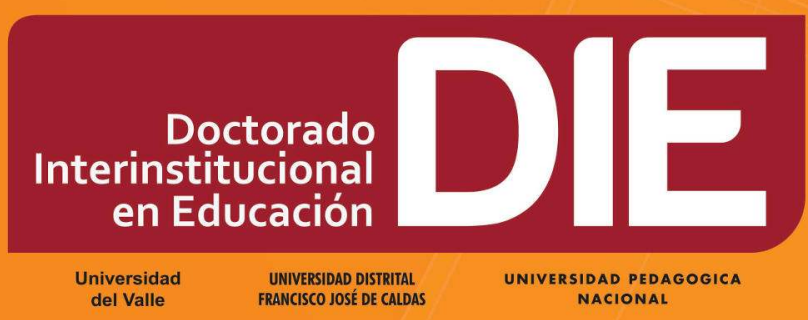






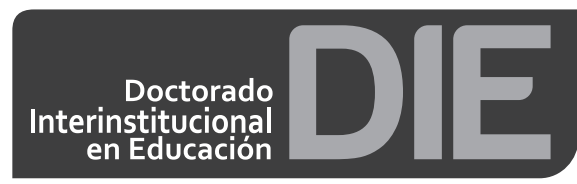

$\begin{gathered}\text { Universidad } \\ \text { del Valle }\end{gathered}$
ERANESSIDAD DISTRITIA
FRASC JOSE DE CALAS

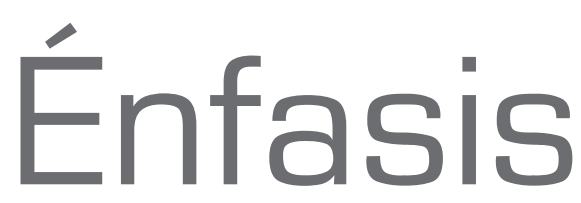

Libros de la serie Énfasis

Doctorado Interinstitucional en Educación

UNIVERSIDAD DISTRITAL

FRANCISCO JOSÉ DE CALDAS 



\section{Énfasis}

Libros de la serie Énfasis

Doctorado Interinstitucional en Educación

\section{Enseñando geometría con tecnología digital: \\ una propuesta desde la Teoría de las Situaciones Didácticas}

Martín Eduardo Acosta Gempeler y Jorge Enrique Fiallo Leal

Universidad Distrital Francisco José de Caldas 


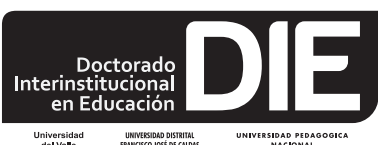

$\underset{\substack{\text { Universidad } \\ \text { del Valle }}}{\cos }$
Comité Editorial-CADE

\section{Álvaro García Martínez}

Presidente CADE

William Manuel Mora Penagos

Representante de los grupos de investigación: Investigación en Didáctica de las Ciencias, Interculturalidad, Ciencia y TecnologíaINTERCITEC, GREECE y del Grupo Didáctica de la Química-DIDAQUIM, del Énfasis de Educación en Ciencias.

Juan Carlos Amador Baquiro

Representante de los grupos de investigación: Moralia, Estudios del Discurso, Filosofía y Enseñanza de la Filosofía, Grupo de investigación Interdisciplinaria en Pedagogía de Lenguaje y las Matemáticas-GIIPLyM y Jóvenes, Culturas y Poderes, del Énfasis de Lenguaje y Educación.

Rodolfo Vergel Causado

Representante de los grupos de investigación: Grupo de Investigación Interdisciplinaria en Pedagogía de Lenguaje y las Matemáticas GIIPLyM, Matemáticas Escolares Universidad Distrital-MESCUD y EDUMAT, del Énfasis de Educación Matemática.

\section{Bárbara García Sánchez}

Representante del grupo de investigación: Formación de Educadores, del énfasis de Historia de la Educación, Pedagogía y Educación Comparada.

Harold Castañeda-Peña Representante de los grupos de investigación: Aprendizaje y Sociedad de la Información y Formación de Educadores, del énfasis de ELT Education.
Universidad Distrital Francisco José de Caldas

Carlos Javier Mosquera Suárez

Rector (e)

Giovanni Rodrigo Bermúdez Bohórquez

Vicerrector Académico

Universidad Distrital Francisco José de Caldas

Comité Editorial Interinstitucional-CAIDE

Carlos Javier Mosquera Suárez

Director Nacional

Alexander Ruiz Silva

Coordinador DIE

Universidad Pedagógica Nacional

Álvaro García Martínez

Director DIE

Universidad Distrital Francisco José de Caldas

Santiago Adolfo Arboleda Franco

Coordinador DIE

Universidad del Valle 
(C) Universidad Distrital Francisco José de Caldas

ISBN Impreso: 978-958-5434-45-5

ISBN Digital: 978-958-5434-46-2

Primera Edición 2017

\section{Preparación Editorial}

Doctorado Interinstitucional en Educación

http://die.udistrital.edu.co/publicaciones

Sede Universidad Distrital Francisco José de Caldas

Aduanilla de Paiba, Edificio de Investigadores, calle 13 No. 31-75

Asistente editorial eventosdie@udistrital.edu.co

PBX: (57+1) 3239300, ext.6330-6334

\section{Fondo de publicaciones}

Universidad Distrital Francisco José de Caldas

www.udistrital.edu.co

Carrera 24 No. 34 - 37

PBX: $(57+1)$ 3239300, ext.6201

publicaciones@udistrital.edu.co

\section{Corrección de Estilo}

Yeniter Poleo

\section{Diseño y Diagramación \\ Diego Calderón}

\section{Impresión}

Cooperativa Editorial Magisterio

Esta edición 2017 y sus características son propiedad de la Universidad Distrital José Francisco Caldas, por lo que queda prohibida la reproducción total o parcial por cualquier medio, sin la autorización previa por escrito de los editores.

Bogotá, Colombia, 2017

Acosta Gempeler, Martín Eduardo

Enseñando geometría con tecnología digital : una propuesta desde la teoría de las situaciones didácticas / Martín Eduardo Acosta Gempeler, Jorge Enrique Fiallo Leal. -- Bogotá: Universidad Distrital Francisco José de Caldas, 2017

90 páginas ; $24 \mathrm{~cm}$.

ISBN 978-958-5434-45-5

1. Geometría - Enseñanza 2. Geometría - Innovaciones tecnológicas 3. Tecnología educativa 4. Computadores en geometría I. Fiallo Leal, Jorge Enrique, autor II. Tít.

516 cd 21 ed.

A1572547

CEP-Banco de la República-Biblioteca Luis Ángel Arango 



\section{Capítulo 1}

1.1. Marco teórico 13

1.2. La geometría, su historia y su enseñanza $\quad 14$

1.3. Geometría en el currículo escolar 21

1.4. La teoría de las situaciones didácticas $\quad 26$

1.5. Implicaciones del marco teórico 35

\section{Capítulo 2}

2.1. Ejemplo de enseñanza de transformaciones: Simetría Axial 41

2.2. Ejemplo de enseñanza de construcciones: El Rectángulo 69

2.3. Ejemplo de actividades con lugares geométricos: La Mediatriz 82

2.4. Ejemplo de actividades de justificación $\quad 85$

$\begin{array}{ll}\text { Bibliografía } & 88\end{array}$

Sobre los autores $\quad 89$ 

Este libro es el resultado del Proyecto Institucional de Uso de la Geometría Dinámica, el cual nace para dar continuidad e institucionalidad al proyecto nacional Incorporación de Nuevas Tecnologías al Currículo de Matemáticas $^{1}$, liderado por el Ministerio de Educación Nacional desde 2000 hasta 2002 y coordinado por la Universidad Industrial de Santander desde 2000 hasta 2008.

Este proyecto constituyó un experimento a gran escala del uso de la tecnología en la enseñanza de las matemáticas en secundaria. Profesores de colegio y universidad trabajaron en equipo para enfrentar los retos planteados por la introducción de las herramientas digitales. Como fruto de esa experiencia se identificaron múltiples transformaciones debido al impacto de esas herramientas: transformación de las concepciones y prácticas matemáticas; transformación de las relaciones entre los profesores y el saber; entre los alumnos y el saber; entre los alumnos y los profesores; transformación de las formas de organización de la clase y de las responsabilidades administrativas en la institución; y transformación del currículo de matemáticas, entre otras. Con el paso de los años el uso de la tecnología en algunos de los colegios participantes se abandonó. Los profesores formados no lograron multiplicar el conocimiento recibido al interior de las instituciones, y terminaron aislados de sus colegas de trabajo. Además, aunque los profesores capacitados aplicaron algunas actividades de clase con sus estudiantes, no lograron crear nuevas actividades que se ajustaran a los planes de área y de aula exigidos en las instituciones.

En respuesta a esas debilidades encontradas, el grupo de investigación Edumat-UIS formuló el Proyecto Institucional de Uso de la Geometría Dinámica, mediante el uso de la Ingeniería Didáctica como marco metodológico y la Teoría de las Situaciones Didácticas como marco teórico para el análisis de las actividades. El objetivo del proyecto se centró precisamente en la transformación curricular con base en que la incorporación de las tecnologías en el aula abre un conjunto de posibilidades en el campo de la enseñanza y el aprendizaje de las matemáticas, pero también nuevas necesidades de formación de los profesores de matemáticas pues esto exige el conocimiento de nuevas estrategias de enseñanza, diseño de materiales y nuevas relaciones de trabajo entre el profesor y su propia práctica docente.

$1 \quad$ Ver documentos del proyecto del Ministerio. 
Nuestra contribución ante estas exigencias consiste, con este libro, en dar los primeros pasos para el desarrollo de un currículo de geometría basado en el uso del software de geometría dinámica y supone un uso intensivo del mismo. Una de las características fundamentales de esta intención es la formulación de un marco teórico de Didáctica de las Matemáticas que explica y describe los procesos de aprendizaje y de enseñanza y precisa el rol de las tecnologías en esos dos procesos.

Ese marco teórico permite, además, diseñar actividades didácticas para alcanzar objetivos de aprendizaje específicos, y analizar y evaluar su implementación en situaciones reales de clase. De modo que el presente documento expone ese marco teórico y lo aplica en actividades que se diseñaron para alumnos de grados sexto, séptimo, octavo y noveno.

Este libro abre el camino para incorporar las tecnologías digitales en la enseñanza de las matemáticas de manera asertiva y, además, resulta una estrategia de formación permanente para el profesor de matemáticas. 


\subsection{Marco teórico}

Para la comunidad de educadores matemáticos es importante tener lineamientos claros que los orienten al tomar decisiones, asumir roles y comprender procesos. Para facilitar la comprensión de tales lineamientos, se diseñaron tres diagramas que sintetizan las ideas teóricas orientadoras del proyecto.

- La geometría, su historia y su enseñanza

Este primer diagrama intentará responder las siguientes preguntas:

¿Qué es la geometría? ¿Cuáles son los objetivos de enseñar geometría en el colegio? ¿Cuál es el rol del software de geometría dinámica en el proceso de enseñanza y de aprendizaje de la geometría?

- Geometría en el currículo escolar

Diagrama en el cual se presenta la enseñanza de la geometría como una evolución de los procesos de razonamiento geométrico, identificando las herramientas didácticas que permiten pasar de un estadio al siguiente.

- La Teoría de las Situaciones Didácticas

Es el más complejo de los diagramas pues intenta responder a las siguientes preguntas: ¿Cómo aprenden los niños? ¿Cuál es el rol de la tecnología en el aprendizaje? ¿Cuál es el rol del profesor en los procesos de aprendizaje? ¿Cómo diseñar y administrar una actividad de clase que produzca aprendizaje?

Para presentarlos, decidimos inicialmente mostrar el diagrama con todos sus elementos. Después, a medida que avanzamos en la explicación, se reconstruirá cada diagrama y se reflexionará sobre cada elemento que lo compone. 


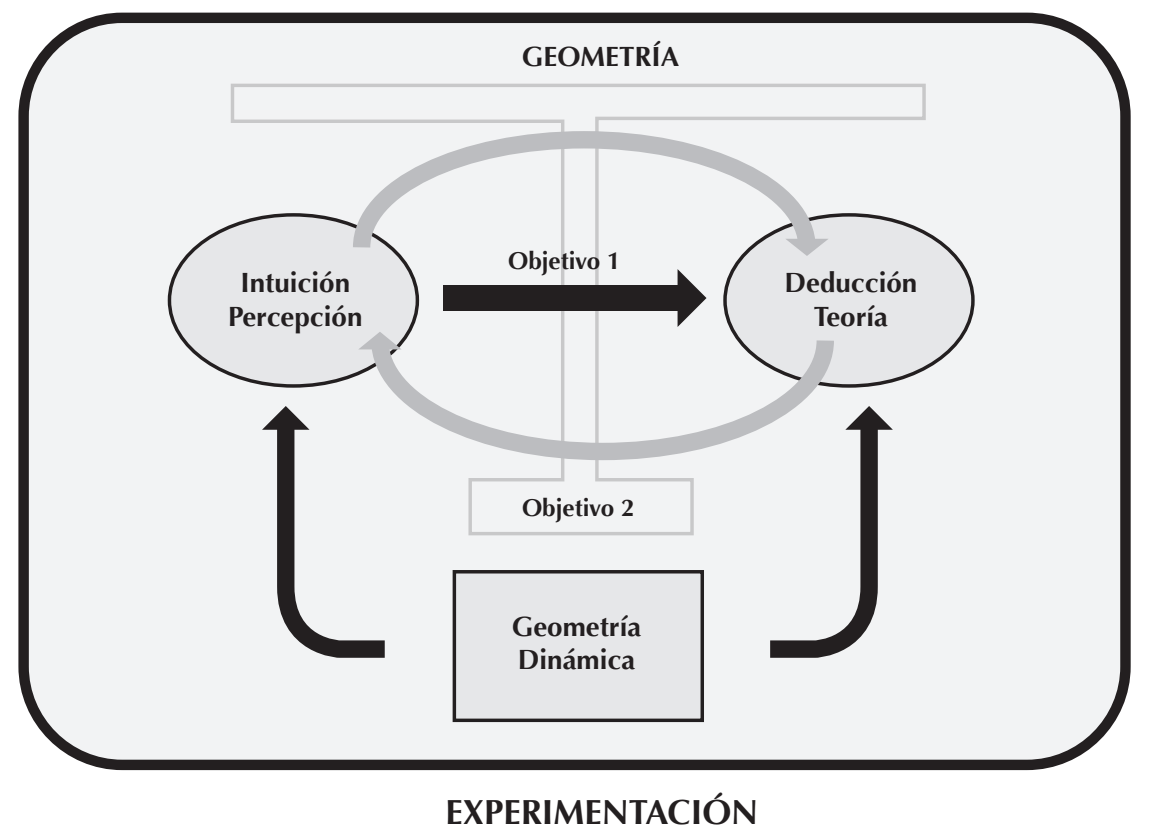

Figura 1. La geometría, su historia y su enseñanza

Primero que todo, asumimos la geometría como el área de las matemáticas que se ocupa de razonar con figuras. Por lo tanto, la geometría comprende dos aspectos fundamentales: los procesos de percepción de las figuras, y los procesos de razonamiento utilizando las figuras. La geometría se caracteriza entonces por una tensión permanente entre dos polos: el polo de la percepción y el polo de la teoría; el polo de la intuición y el polo de la deducción (Figura 2). 

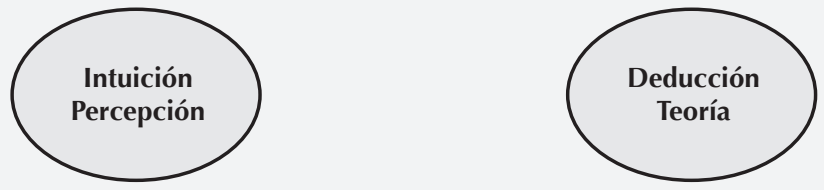

Figura 2. Intuición, percepción vs deducción, teoría

Los Ilamamos "polos" para resaltar su carácter de oposición y de mutua dependencia. Cada uno de ellos atrae la actividad matemática de la geometría, pero no es posible hacer geometría si se prescinde de uno de ellos. Esta idea de mutua dependencia de la intuición y la deducción, de la percepción y la teoría es resultado de una evolución histórica de la geometría y de su enseñanza, que vamos a examinar sucintamente.

Los griegos fueron los primeros en desarrollar el aspecto teórico de la geometría. Los Elementos de Euclides sintetizan el esfuerzo de dar un fundamento teórico-deductivo a la actividad geométrica. Durante los siglos posteriores se consideró a la geometría como la ciencia por antonomasia, por el hecho de ser totalmente deductiva y describir o explicar al mismo tiempo la realidad. Asimismo, se consideraba la geometría como el fundamento de las matemáticas.

Sin embargo, la Ilamada Geometría Euclidiana contiene muchos elementos de intuición y percepción. Para señalar solo un ejemplo muy conocido, el concepto de congruencia de figuras en la geometría euclidiana se basa en la posibilidad de superposición, que es un hecho perceptivo.

Los matemáticos posteriores a los griegos comenzaron a encontrar defectos en la estructura deductiva de la geometría euclidiana. En especial, el quinto 
postulado de Euclides fue materia de debate y reformulación, buscando una forma de hacerlo evidente o de demostrarlo como un teorema. El resultado de estos esfuerzos condujo a la formulación de las geometrías no euclidianas, como un intento fallido de demostrar por contradicción el quinto postulado de Euclides.

El reconocimiento de las geometrías no euclidianas como geometrías válidas deductivamente pero contradictorias de la realidad produjo una profunda crisis en la comunidad científica y matemática de la época. La geometría dejó de ser la ciencia por antonomasia, pues ya no necesariamente describía la realidad. Comenzó un proceso de desconfianza hacia la percepción y la intuición, y el rigor matemático (entendido como la necesidad de reducir al máximo el papel de la intuición en el razonamiento matemático) se elevó como un valor fundamental. Las matemáticas dejaron de fundamentarse en la geometría, incluso comenzó a señalarse a la geometría euclidiana como fuente de errores conceptuales debido a su fuerte dependencia de la percepción y la intuición; los matemáticos se enorgullecían de poder razonar sin utilizar figuras. En síntesis, trató de eliminarse el polo de la intuición y la percepción en la actividad matemática (Figura 3).

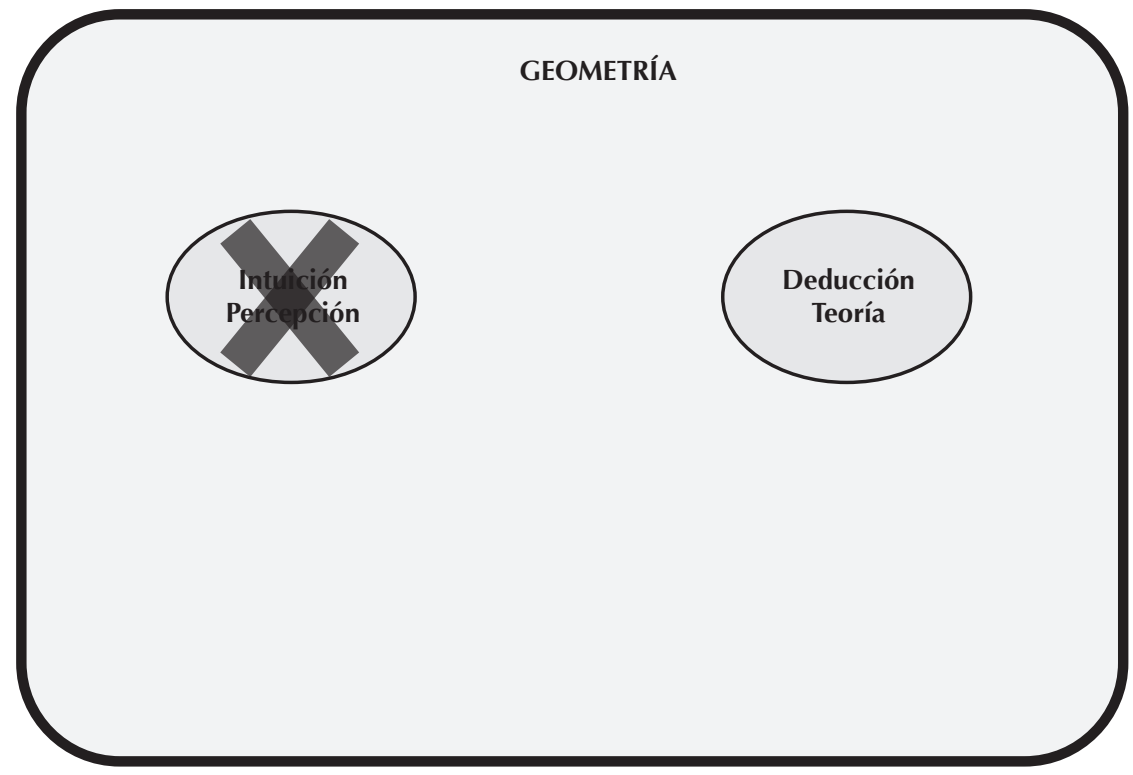

Figura 3. Eliminación de la intuición y la percepción de la geometría 
Esta tendencia llegó a su culmen con los trabajos del grupo Bourbaki, cuyos escritos tuvieron gran influencia en las matemáticas del siglo XX y condujeron al Ilamado movimiento de reforma de las matemáticas modernas. Este movimiento, que fue adoptado en los currículos de matemáticas del mundo entero, tenía como objetivo principal llegar directamente al polo de la deducción y la teoría evitando los errores de la percepción y la intuición (Figura 4).

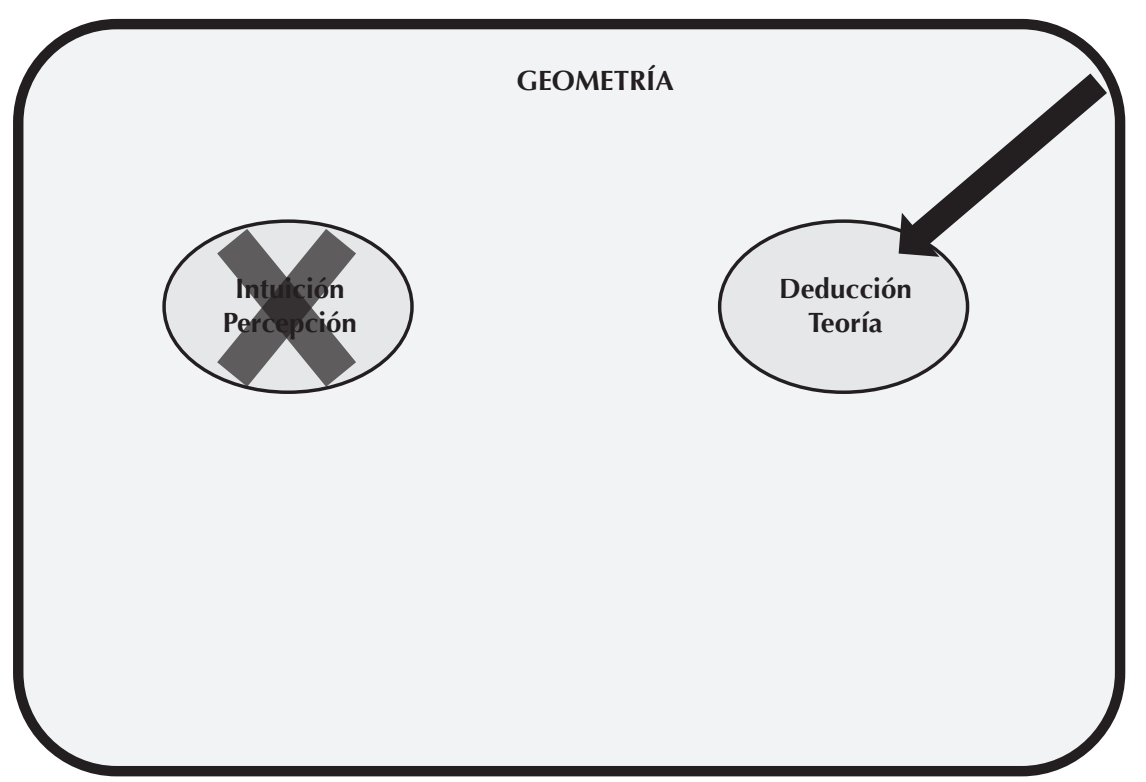

Figura 4. Énfasis en la deducción y la teoría

Esta gran reforma curricular a escala mundial significó el abandono de la enseñanza de la geometría euclidiana, pues la geometría plana pasó a ser un capítulo del álgebra vectorial. La enseñanza de la geometría euclidiana se consideraba inadecuada por su dependencia de las figuras (y por tanto, de la percepción y la intuición), debido a la poca formalización de su lenguaje y a la multiplicidad de métodos y casos particulares que era necesario considerar en la resolución de problemas.

Dos hechos importantes produjeron un cambio de orientación de la epistemología de las matemáticas y del naciente campo de la educación matemática en el siglo XX:

- Por una parte, el teorema de Gödel condujo al abandono del objetivo de rigor absoluto y de unificación definitiva de las matemáticas en una sola teoría autocontenida y totalmente deductiva. 
- Por otra parte, los estudios de psicología cognitiva y de psicología genética despertaron el interés por el origen cognitivo de los conceptos matemáticos (retomando propuestas de matemáticos como Poincaré), al proponer una alternativa no logicista para la fundamentación de las matemáticas.

Así es como hoy en día se reconoce la imposibilidad de independizar los dos polos de la actividad geométrica, y se resalta más bien su mutua dependencia y su complementariedad. Entonces, hoy podemos formular dos grandes objetivos de la enseñanza de la geometría:

El primero es introducir a nuestros alumnos en el mundo de la teoría, pero a partir del mundo de la percepción (Figura 5).

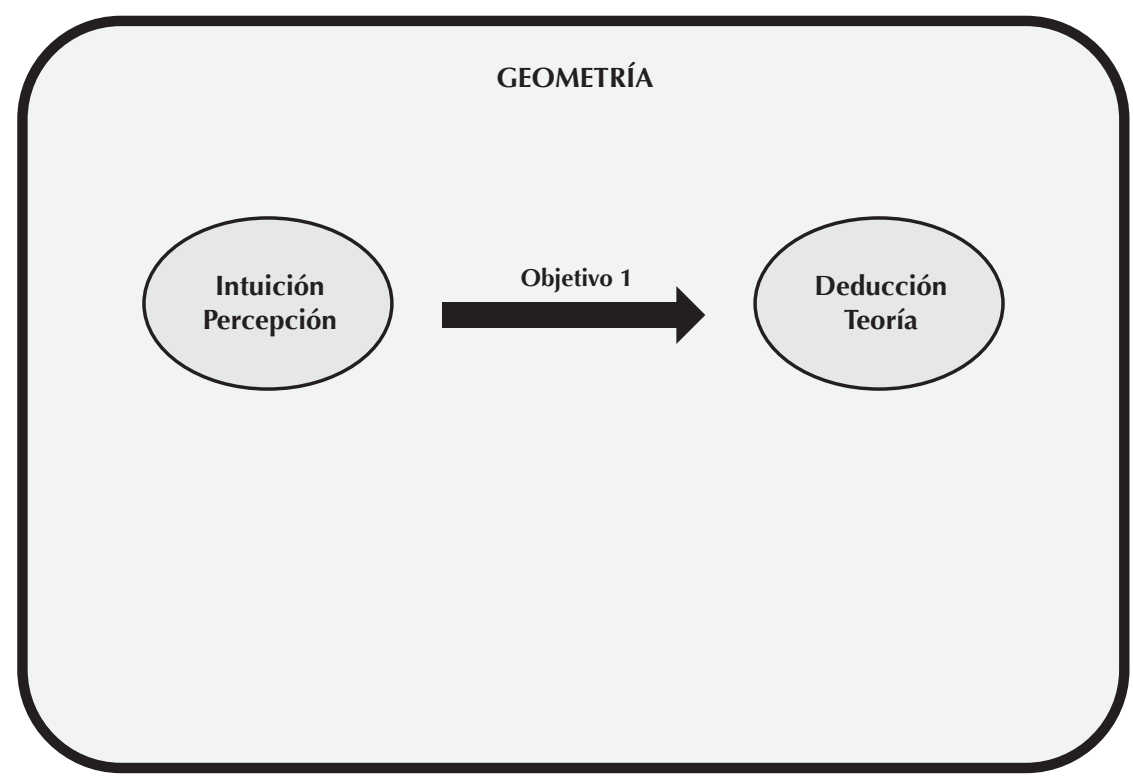

Figura 5. Objetivo 1 de la enseñanza de la geometría

Los profesores de matemáticas somos responsables de desarrollar en nuestros alumnos el polo de la teoría. Es decir, debemos buscar que nuestros alumnos se convenzan de que la teoría permite resolver problemas de manera eficiente. Pero en ese esfuerzo de abrir los ojos de nuestros alumnos al mundo de la teoría, no podemos ignorar ni repudiar los procesos de percepción e intuición presentes en toda actividad geométrica; más bien debemos apoyarnos en esos procesos para introducir a nuestros alumnos en el mundo de la teoría. 
El segundo objetivo de la enseñanza de la geometría es lograr el equilibrio entre los dos polos de la actividad geométrica (Figura 6).

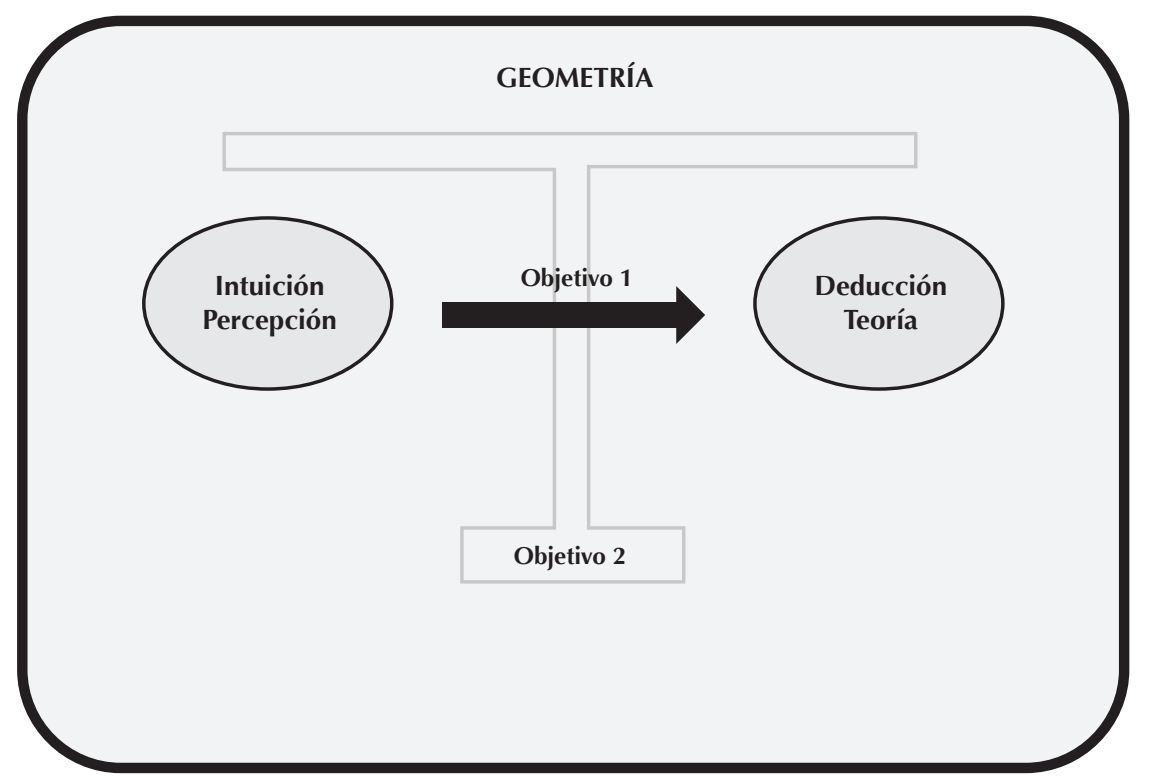

Figura 6. Objetivo 2 de la enseñanza de la geometría

Es decir, que no haya predominio de uno de los dos en la actividad geométrica de los alumnos. Es normal que en un comienzo el polo de la intuición y la percepción sea predominante, pero en la medida en que se cumpla el primer objetivo, ese dominio debe ser remplazado por un equilibrio. Para lograrlo, los profesores debemos hacer énfasis en los procesos de razonamiento teórico, sin llegar al extremo de subvalorar o dejar de lado los procesos de intuición y percepción.

¿Cómo lograr este segundo objetivo de equilibrio entre los dos polos en la actividad geométrica de nuestros alumnos? Al multiplicar las relaciones entre los dos polos. Se debe buscar que nuestros alumnos, cuando trabajen de manera perceptiva con las figuras, recurran a la teoría para guiar y controlar la percepción, y cuando trabajen de manera deductiva en los enunciados teóricos, recurran a la percepción para representar y comprender la teoría (Figura 7). 


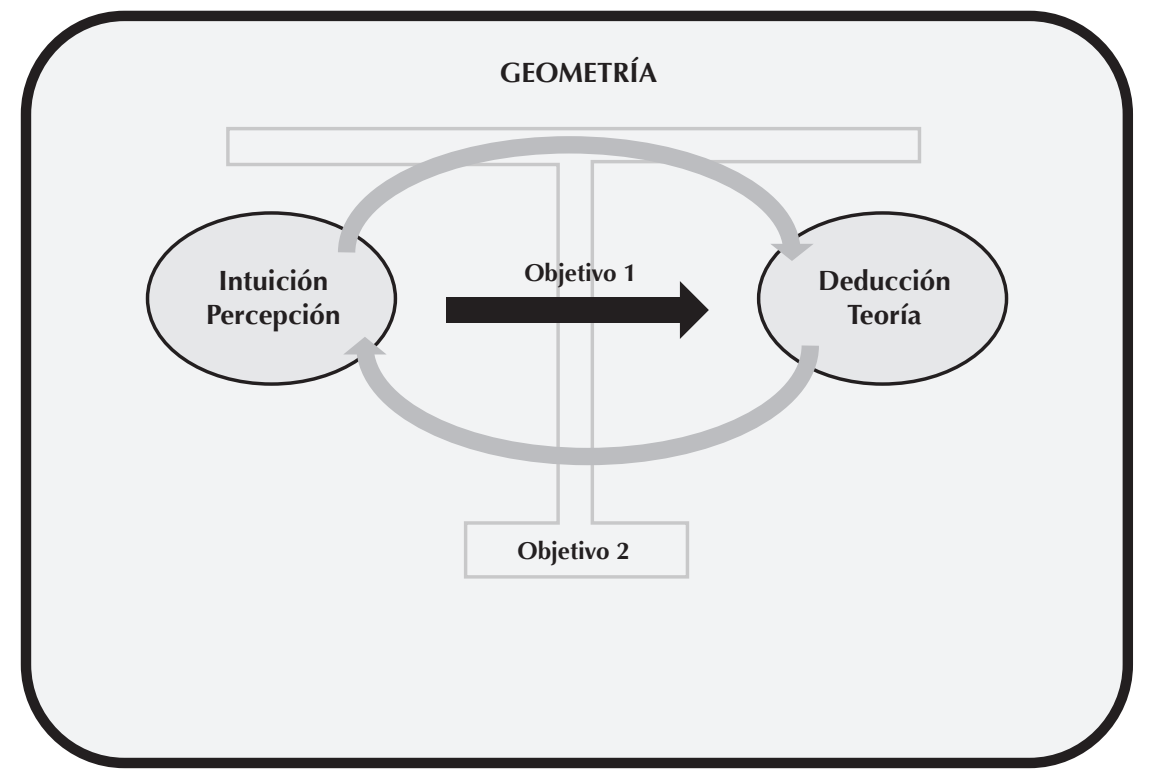

Figura 7. Trabajo equilibrado entre los dos polos

Precisamente es allí donde cobra importancia el software de geometría dinámica (Figura 8). Los objetos de la geometría dinámica son objetos perceptibles: podemos verlos, podemos manipularlos en la pantalla del computador.

Sin embargo, el comportamiento de tales objetos responde a leyes teóricas de la geometría, y por lo tanto también son objetos teóricos (Figura 8).

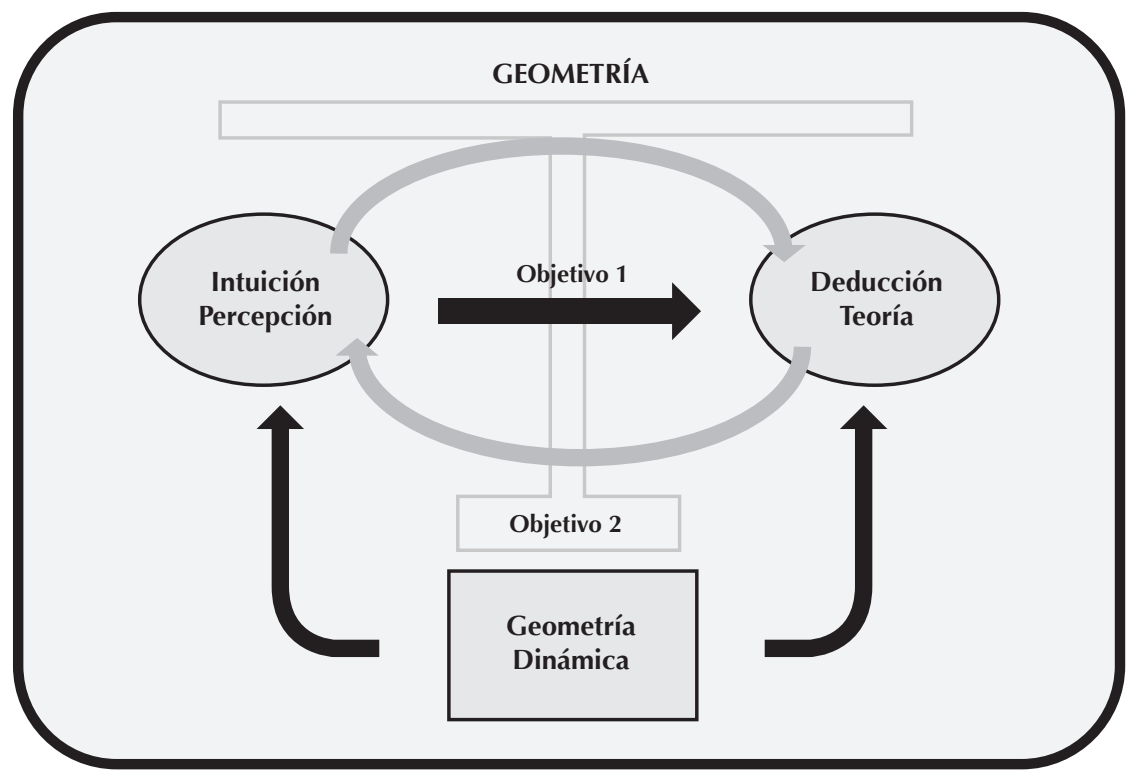

Figura 8. Papel del software de geometría dinámica 
Estos objetos híbridos (a la vez perceptivos y teóricos) permiten precisamente establecer relaciones entre los dos polos, para lograr el equilibrio de los mismos en la actividad geométrica.

La actividad de experimentación con los objetos de la geometría dinámica es una actividad productora de relaciones entre los dos polos. La experimentación implica no solamente una manipulación perceptiva de los objetos, sino una postura teórica que busca explicar y predecir el comportamiento de los mismos. La actividad de experimentación implica enunciar conjeturas y verificarlas experimentalmente. Las conjeturas que sean validadas se convertirán en leyes teóricas que permitirán guiar y controlar la percepción (Figura 9).

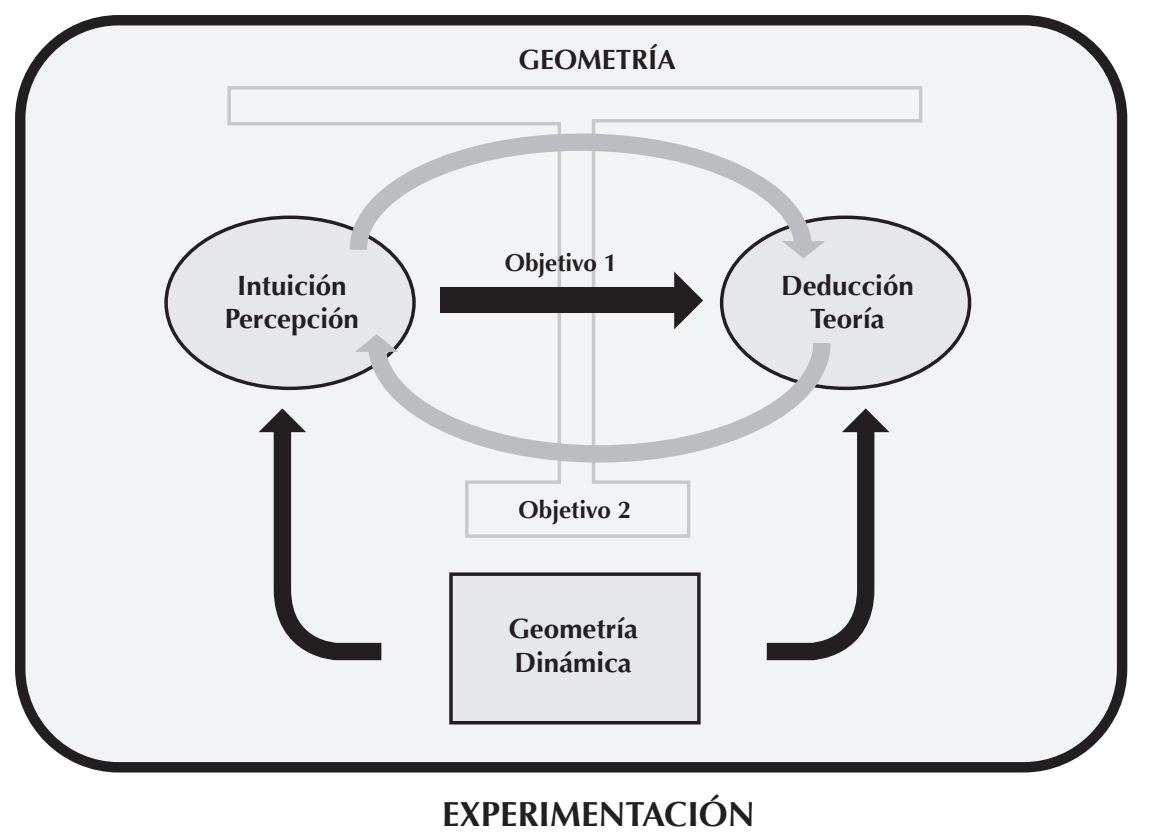

Figura 9. La actividad de experimentación 
Podemos considerar cuatro etapas de la geometría escolar, ilustradas en la Figura 10:

I. Geometría de las Formas

II. Geometría de las Construcciones

III. Geometría de las Justificaciones

IV. Geometría de las Demostraciones

A continuación ampliaremos cada una de estas etapas:

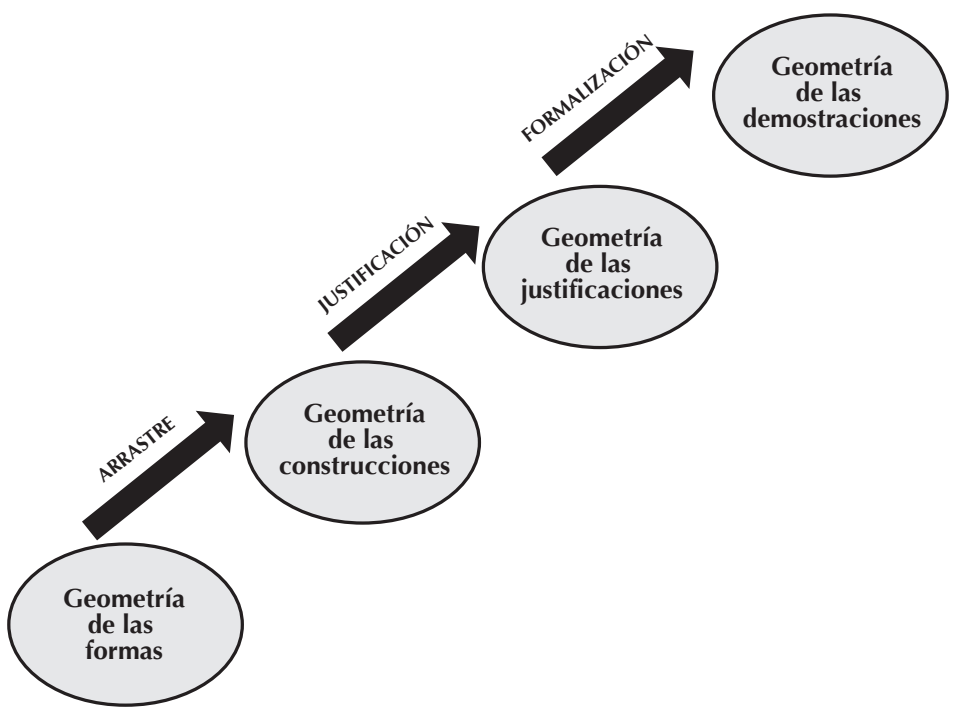

Figura 10. Evolución de la geometría escolar

La primera etapa es la Geometría de las Formas. Se enseña en los primeros grados de primaria y consiste fundamentalmente en identificar las figuras geométricas y distinguirlas entre sí. Las operaciones mentales trabajadas en esta geometría son la clasificación y la diferenciación. Las figuras geométricas son asimiladas como formas globales correspondientes a imágenes mentales prototípicas (yo sé que "esto" es un rectángulo, "esto" es un círculo, "esto" es un triángulo, etcétera). En la segunda etapa, Geometría de las Construcciones, ya no hay una preocupación por clasificar e identificar, sino 
más bien por analizar y construir. En esta etapa las figuras no se consideran como formas globales sino compuestas por objetos más básicos (puntos y líneas), con relaciones especiales entre ellos (paralelismo, perpendicularidad, pertenencia, equidistancia, etcétera). Es necesario un cambio en la forma de concebir e identificar las figuras, y un cambio en las ideas teóricas que orientan la actividad geométrica.

En esta etapa los alumnos deben identificar las propiedades geométricas (las relaciones entre los objetos que componen una figura) como elementos fundamentales en la definición de las figuras. Para producir ese cambio, utilizamos como herramienta didáctica el arrastre de validación en las construcciones: una construcción será correcta si al arrastrar los elementos que la componen no pierde sus propiedades; por el contrario, será incorrecta si dichas propiedades se pierden.

La validación por arrastre permite a los alumnos abandonar las estrategias únicamente perceptivas (tratar de obtener una forma global de acuerdo con una imagen mental), pues los dibujos producidos con estas estrategias pierden la forma al arrastrar. A su vez, permite definir las propiedades geométricas como aquellas condiciones que deben mantenerse durante el arrastre para garantizar que las formas no se pierdan. Durante esta etapa entonces se estudiarán las figuras fundamentales, las propiedades geométricas que sirven para definirlas y los procedimientos de construcción que permiten obtener dichas propiedades.

En la tercera etapa, correspondiente a la Geometría de las Justificaciones, ya se ha coleccionado una serie de procedimientos de construcción que garantizan las propiedades de las figuras. En esta etapa se comienzan a utilizar esos procedimientos como justificación de que en una figura ya construida se cumplen o no determinadas propiedades. Aunque el cambio puede parecer sutil, en realidad es fundamental: en la etapa anterior el acento estaba en la producción de las figuras, en esta etapa el énfasis está en el razonamiento: ¿Por qué esta figura construida tiene o no determinada propiedad? El razonamiento y la demostración se deben ver como modos de desarrollar y codificar conocimientos sobre las propiedades de la figura.

La herramienta didáctica para pasar de la geometría de las construcciones a la geometría de las justificaciones es la necesidad de justificar. Es importante que los alumnos descubran que algunas de las propiedades de las figuras construidas provienen directamente de las herramientas o procedimientos de construcción que se utilizaron, pero otras no. Estas propiedades que cumplen las figuras, pero que no fueron producidas directamente por procedimientos de construcción, conducen a desarrollar la idea de implicación lógica: si se 
cumplen determinadas propiedades, entonces también tienen que cumplirse otras. La enunciación de estas implicaciones constituye lo que llamamos reglas teóricas de la geometría.

Podríamos decir que en esta etapa se está entrando en el mundo de la demostración, vista desde una perspectiva amplia, como "el proceso que incluye todos los argumentos planteados por el alumno para explicar, verificar, justificar o validar con miras a convencerse a sí mismo, a otros alumnos y al profesor de la veracidad de una afirmación matemática" (Fiallo, 2011). Los alumnos buscan en una demostración una explicación, se esfuerzan en leer la demostración como herramienta para convencerse y convencer a otros.

En el contexto didáctico, el papel explicativo de la demostración y su comprensión parecen más importantes que la aceptación de la validez de un teorema; en consecuencia, una demostración debe fomentar la comprensión y tener en cuenta el contexto de la clase y lo vivido por los alumnos.

Desde esta perspectiva, en esta etapa los alumnos empiezan a construir demostraciones de acuerdo con su razonamiento y sus conocimientos, primando las demostraciones empíricas (Fiallo, 2011), caracterizadas por el uso de ejemplos como el principal (puede ser el único) elemento de convicción.

Puede ser que el alumno justifique con argumentos basados en elementos perceptivos, elementos geométricos o relaciones detectadas en la figura; justifique con un ejemplo cuidadosamente seleccionado, porque presume que en cualquier otro caso va a dar el mismo resultado; justifique con argumentos basados en las construcciones realizadas sobre la figura o en la forma de construir la figura; use una figura representante de una clase y justifique con argumentos basados en propiedades y relaciones generales descubiertas en esa figura, o argumentos basados en propiedades matemáticas aceptadas, pero que no son resultado de observaciones o propiedades encontradas en la figura, sino que al trabajar sobre ella se recuerdan. En los dos últimos casos, se produce un razonamiento abstracto que involucra propiedades geométricas generales y no propiedades específicas de la figura, en este sentido, podemos decir que los estudiantes están empezando a considerar el paso al razonamiento deductivo.

Según lo anterior, el papel del profesor consistirá en mostrarle al alumno la debilidad de los argumentos empíricos, por medio de contraejemplos o preguntas que conduzcan al estudiante a pensar en la necesidad del uso de las reglas teóricas. En ningún momento se trata de aprobar o rechazar determinada forma de argumentación, sino de cuestionar su validez y su funcionalidad. 
La cuarta etapa es la Geometría de las Demostraciones. En esta ya hay un énfasis en las reglas teóricas de la geometría, es decir, en las implicaciones y su utilización en la justificación, que es lo que llamamos una demostración deductiva. La herramienta didáctica para pasar de la tercera a la cuarta etapa es la formalización, es decir el énfasis en la forma de los enunciados y las relaciones entre ellos.

Una demostración deductiva encadena las deducciones por "reciclaje". La deducción se ocupa de los argumentos que apoyan la necesidad de una conclusión sobre una o varias premisas: siendo verdaderas las premisas, la conclusión debe serlo también.

Para comprender la naturaleza de un paso de demostración, se está obligado a interesarse por el estatus de las proposiciones. Toda proposición tiene un estatus particular: dato, conclusión, teorema, etcétera. La proposición, teniendo el mismo contenido, puede tener dos estatus diferentes en dos pasos diferentes. Así la conexión entre dos pasos de deducción es tal que la conclusión del primer paso se convierte en premisa del paso posterior.

La deducción es una clase de "mecanismo" que el estudiante aprende a fin de construir las demostraciones. Ella no se desarrolla espontáneamente en su actividad. Por el contrario, puede parecer artificial y complicada.

La demostración deductiva es una forma de pensar que se basa en operaciones mentales sin la ayuda de ejemplos específicos, o si se usa un ejemplo, es para ayudar a organizar la demostración. En una deducción formal solamente se mencionan aspectos genéricos de la propiedad discutida. Es, por tanto, la clase de demostración formal matemática encontrada en el mundo de los investigadores de las matemáticas. La demostración deductiva es un caso particular de argumentación con unas características específicas: tiene como objetivo validar un enunciado, es una justificación racional, busca certificar la verdad dentro de una teoría matemática de una determinada manera, tiene como objetivo la búsqueda de las razones de la "verdad", tiene el objetivo de validar una determinada tesis.

La demostración deductiva además de las funciones de explicación, convicción y descubrimiento cumple con las funciones de comunicación y axiomatización, por lo que es importante que el profesor ayude al estudiante a comprender esta forma de razonar y de organizar las ideas matemáticas. 


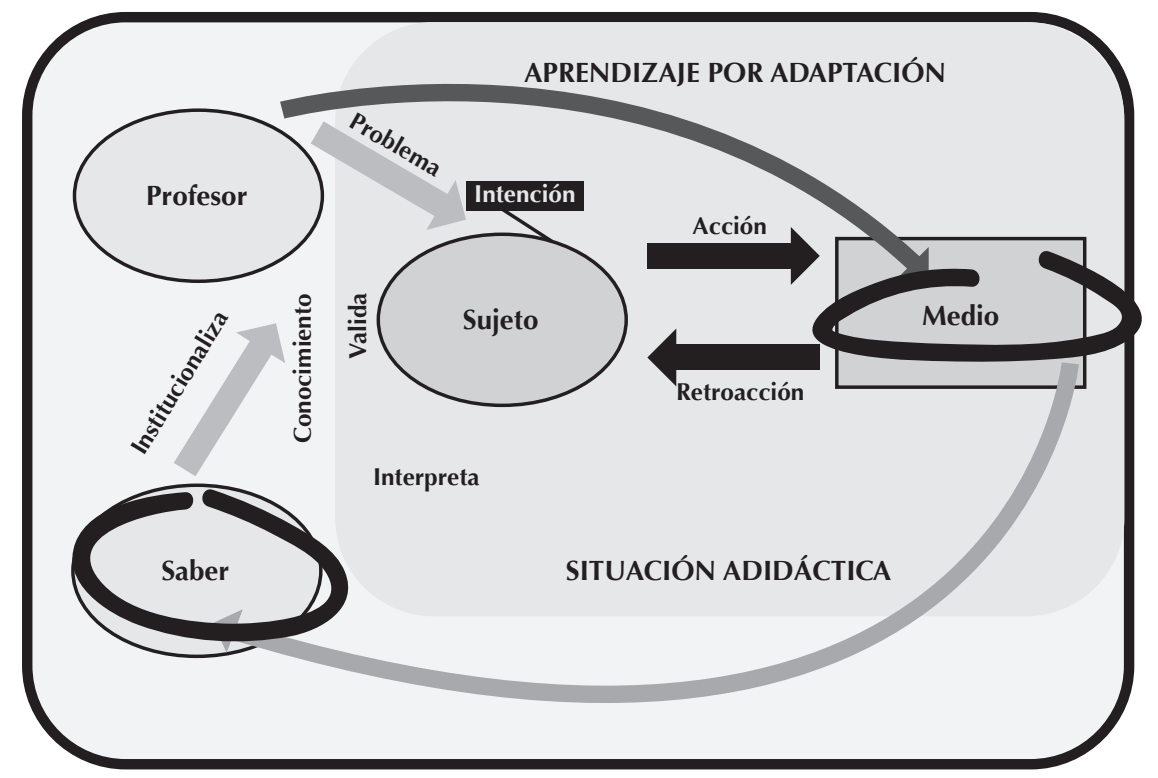

Figura 11. Esquema general de la Teoría de las Situaciones Didácticas

En este proyecto hemos asumido como marco teórico didáctico la Teoría de las Situaciones Didácticas (TSD) (Brousseau, 1986). Los conceptos de esta teoría que servirán para orientar el diseño y el análisis de las actividades de clase son:

- Aprendizaje por adaptación

- Situación adidáctica

- Situación didáctica

- Proceso de devolución

- Proceso de institucionalización

\subsubsection{Aprendizaje por adaptación}

El concepto central de la TSD es el de aprendizaje por adaptación (Figura 12). Podemos dar una primera definición del aprendizaje por adaptación como aquel aprendizaje que se produce sin la mediación de un profesor. 
APRENDIZAJE POR ADAPTACIÓN
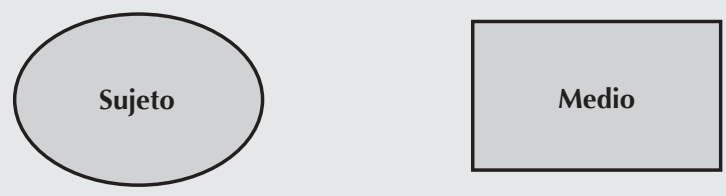

Figura 12. Aprendizaje por adaptación

En efecto, el concepto de aprendizaje por adaptación proviene del campo de la biología, que considera los procesos de adaptación de los seres vivos al medio que los rodea. Para la TSD, el aprendizaje por adaptación es aquel producto de la interacción entre un sujeto y un medio (por el momento entenderemos el medio como una entidad externa al sujeto, y desprovista de intencionalidad; no es otro sujeto).

Vamos a examinar los elementos de esta interacción entre el sujeto y el medio. El primer elemento es la intención del sujeto. Es decir, el sujeto tiene una necesidad, un propósito, un objetivo (Figura 13).

APRENDIZAJE POR ADAPTACIÓN

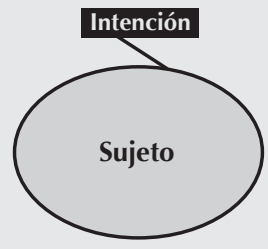

Medio

Figura 13. Primer elemento: intención del sujeto 
El segundo elemento de la interacción es la acción para alcanzar su intención, el sujeto realiza una acción sobre el medio (Figura 14).

\section{APRENDIZAJE POR ADAPTACIÓN}

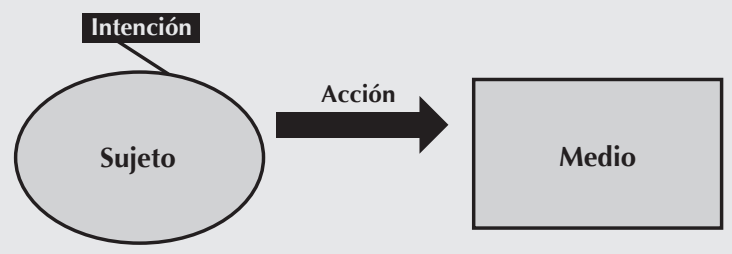

Figura 14. Segundo elemento: acción sobre el medio

El tercer elemento es la retroacción: el medio reacciona a la acción del sujeto, y esta reacción del medio recibe el nombre de retroacción (Figura 15).

\section{APRENDIZAJE POR ADAPTACIÓN}

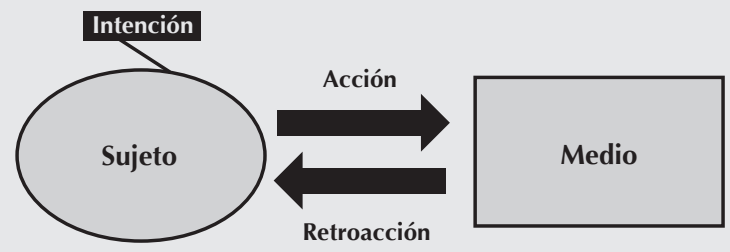

Figura 15. Tercer elemento: retroacción del medio

El cuarto elemento es la interpretación: el sujeto interpreta la retroacción del medio, que adquiere un sentido para él (Figura 16). 
APRENDIZAJE POR ADAPTACIÓN

Interpreta

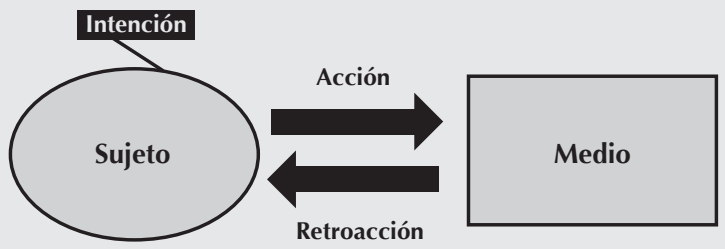

Figura 16. Cuarto elemento: interpretación del sujeto

El quinto elemento de la interacción es la validación: el sujeto valida su acción; es decir, puede decidir si la acción realizada le sirvió para alcanzar su intención o no (Figura 17).

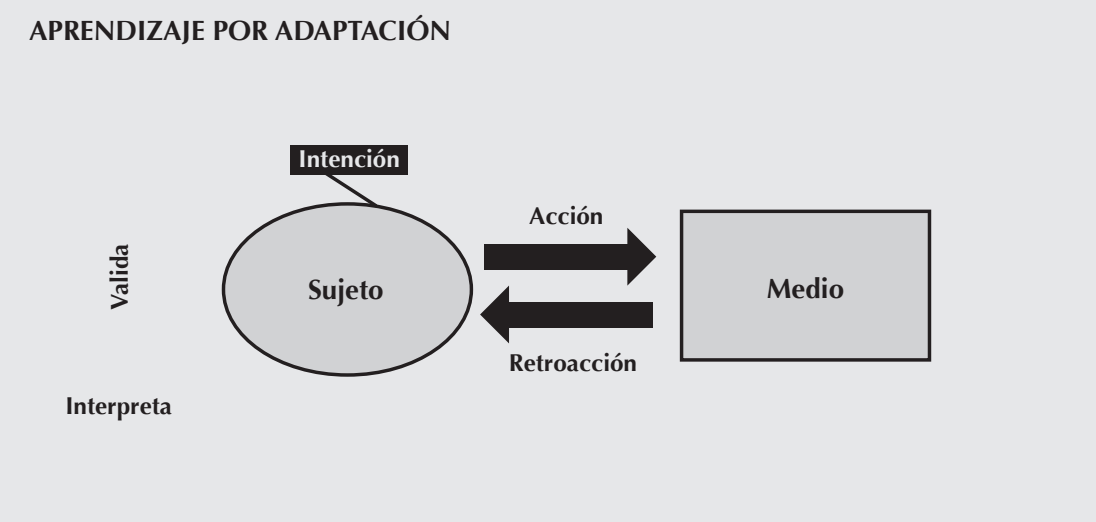

Figura 17. Quinto elemento: validación del sujeto

Esta validación puede tomar dos valores: validación negativa, en cuyo caso el sujeto abandonará la acción realizada y comenzará un nuevo ciclo de interacción con una acción diferente; o validación positiva, en cuyo caso el sujeto reforzará la acción, es decir, la integrará como una respuesta automática a su intención. De estos cinco elementos de la interacción del sujeto con el medio, solo son observables la acción y la retroacción pues 
los demás son internos al sujeto. Pero también son observables los efectos de la validación (cambio o refuerzo de la acción). Estos dos últimos son signos de aprendizaje: cuando el sujeto abandona una acción y la cambia por otra, o cuando el sujeto refuerza una acción, es decir que observamos un uso reiterado de la acción.

Decimos que se da un aprendizaje por adaptación cuando el sujeto, al interactuar con el medio, cambia de acciones o refuerza las acciones que realiza para alcanzar sus intenciones. Como puede apreciarse, en este análisis del aprendizaje no consideramos la intervención de un profesor. A continuación aclararemos el rol del profesor en el proceso de enseñanza según la TSD.

\subsubsection{Situación didáctica y situación adidáctica}

La TSD define una situación didáctica como aquella en la que intervienen tres factores: un profesor, un alumno y un saber. El profesor es alguien que quiere transmitir el saber al alumno, el alumno es quien quiere aprender el saber. Como es evidente, una situación normal de clase es una situación didáctica.

¿Cuál es la relación entre la situación didáctica y el aprendizaje por adaptación? Para la TSD, el profesor no puede transmitir de manera directa el saber al alumno. Todo intento de hacer esta transmisión directa está llamado a fracasar.

Por eso el proceso de enseñanza no puede ser visto únicamente como un proceso de comunicación; es decir, las dificultades de la enseñanza no tienen que ver fundamentalmente con la forma de comunicación del saber (exposición clara, lenguaje comprensible, etcétera). El profesor debe usar una estrategia indirecta para transmitir el saber: crear las condiciones necesarias para que se dé un aprendizaje por adaptación.

Así el ciclo de aprendizaje por adaptación pasa a ser parte de la situación didáctica, y recibe el nombre de situación adidáctica, puesto que en la relación entre el sujeto y el medio no hay ninguna intención de enseñar (Figura 18). 


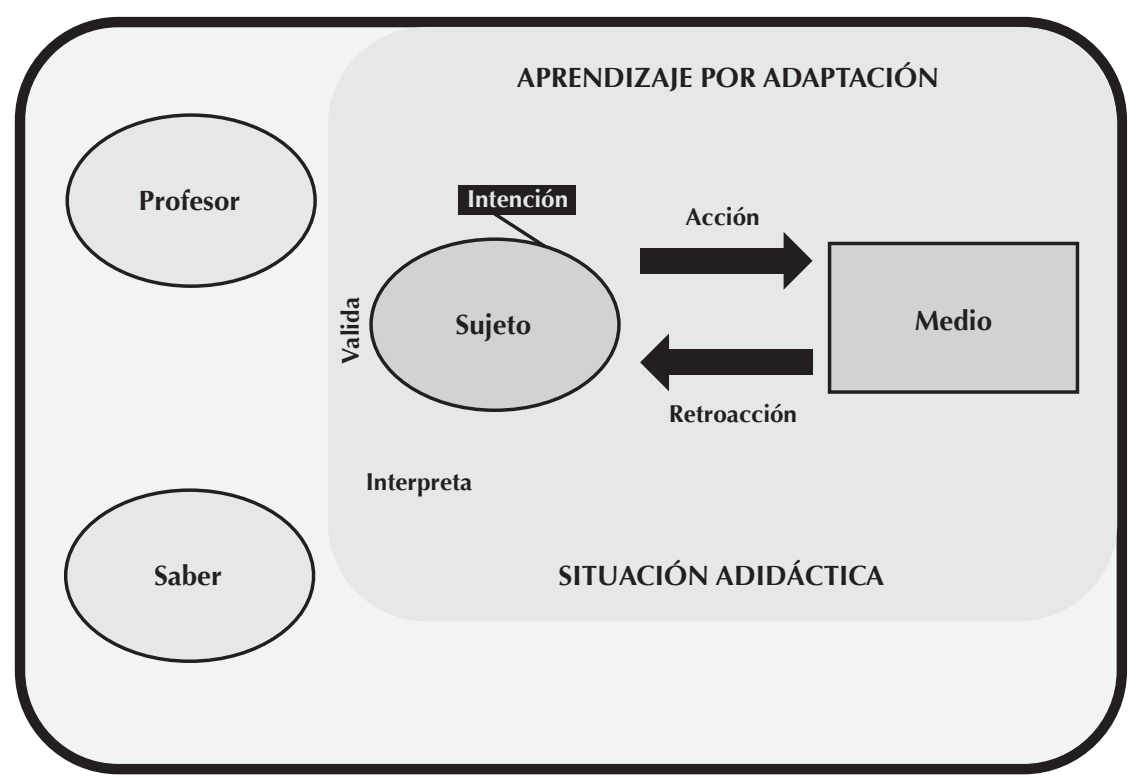

Figura 18. Relación entre la situación didáctica y el aprendizaje por adaptación

A continuación vamos a examinar las relaciones entre la situación didáctica y la situación adidáctica, para aclarar el rol del profesor. Para hacerlo, necesitamos explicitar la distinción que hace la TSD entre saber y conocimiento. Veamos:

En el lenguaje cotidiano, estos dos términos son sinónimos, pero para la TSD son dos conceptos diferentes, puesto que el conocimiento es fruto de una experiencia, y por lo tanto es personal y contextualizado. Cada sujeto tiene un conocimiento diferente, marcado por su experiencia personal y por el contexto de dicha experiencia. Por su parte, el saber es impersonal y descontextualizado y por tanto se opone al conocimiento. El saber es institucional: es el saber sabio, el saber es lo que deciden los sabios, y por lo tanto tiene una estructura y una forma convencionales.

Continuando con nuestro análisis del modelo teórico, podemos decir que el conocimiento es el producto del ciclo de aprendizaje por adaptación, es decir de la situación adidáctica (Figura 19). 


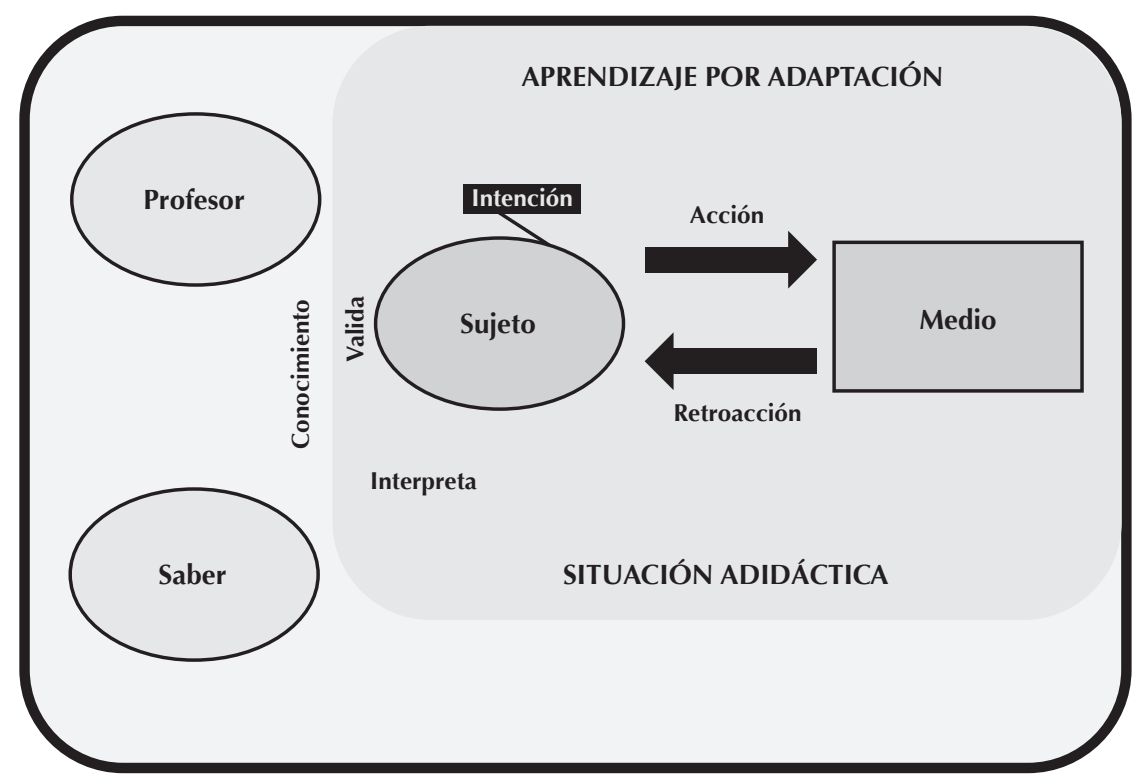

Figura 19. Relación entre la situación didáctica y la situación adidáctica

De modo que el profesor utiliza una situación adidáctica como estrategia para que el alumno construya un conocimiento determinado gracias a la interacción con el medio, y utiliza ese conocimiento personal y contextualizado para transmitir el saber. Ese proceso de enseñanza comprende dos subprocesos: la devolución y la institucionalización.

\subsubsection{Devolución e Institucionalización}

El profesor utiliza una situación adidáctica para que los alumnos construyan un conocimiento determinado. La preparación de una situación adidáctica implica la elaboración de un problema y de un medio. El problema desencadena la intención del sujeto, y el medio posibilita (o imposibilita) determinadas acciones, y ofrece retroacciones que el sujeto puede interpretar con el fin de validar (o invalidar) sus acciones (Figura 20). 


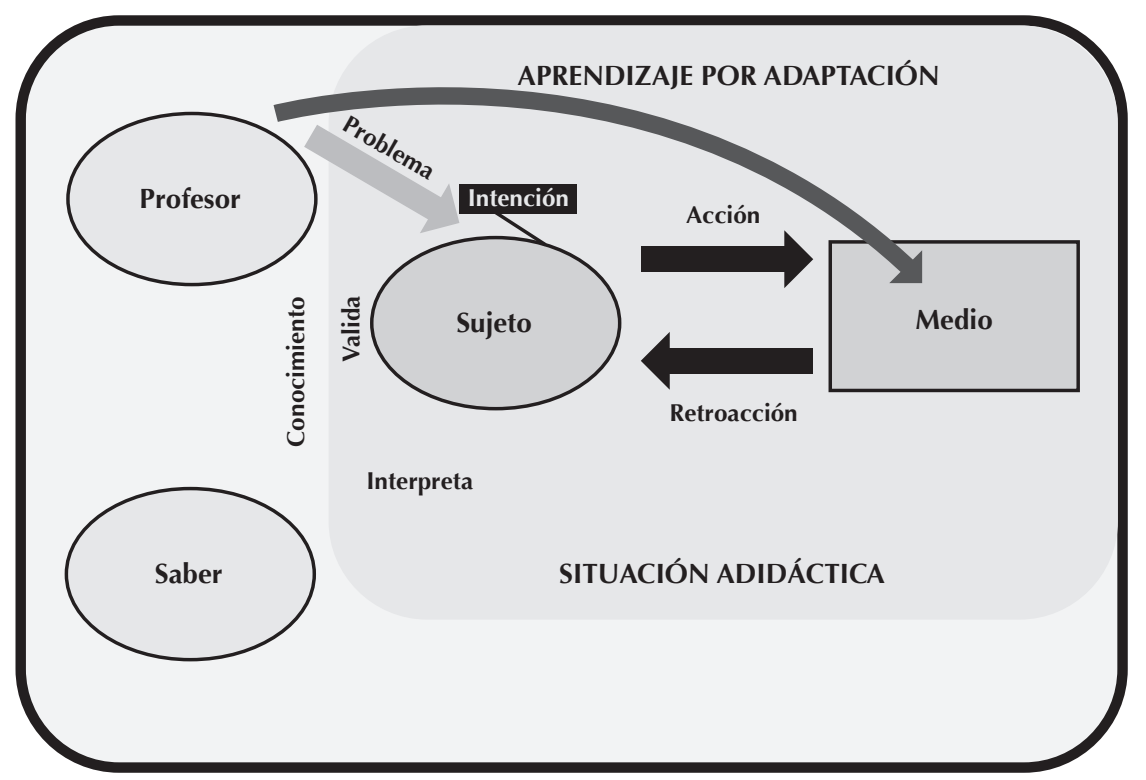

Figura 20. Devolución e institucionalización

Naturalmente, al preparar el medio el profesor debe tener en cuenta cuáles son las posibles acciones que realizará el sujeto, y cuáles son las retroacciones que debe generar el medio para que el ciclo de interacción produzca un aprendizaje por adaptación. Igualmente, al preparar el problema el profesor debe prever que ese problema desencadene una intención y unas acciones susceptibles de generar retroacciones adecuadas del medio. La TSD Ilama devolución al proceso de poner en funcionamiento una situación adidáctica, al entregar al alumno un problema y un medio adecuados y acompañar el proceso para que el ciclo de aprendizaje por adaptación se lleve a cabo.

Una vez haya funcionado la situación adidáctica, los alumnos deben haber construido un conocimiento personal y contextualizado. Entonces el profesor puede realizar la institucionalización, que consiste en explicitar las relaciones entre el conocimiento construido por los alumnos y el saber. El hecho de introducir el saber únicamente a partir de los conocimientos construidos por los alumnos, garantiza que el saber adquiera sentido para los alumnos, quienes pueden relacionarlo con su experiencia personal. Por el contrario, cuando se intenta transmitir directamente el saber, los alumnos están en la incapacidad de relacionarlo con sus experiencias, y por lo tanto no adquiere sentido para ellos. 
El proceso de devolución implica no solamente la preparación del problema y del medio, sino también un determinado comportamiento del profesor durante la situación adidáctica pues ciertas intervenciones podrían impedir el aprendizaje por adaptación.

En efecto, una característica fundamental de la situación adidáctica es la posibilidad que tiene el alumno de validar o invalidar por sí mismo las estrategias que pone en práctica para resolver el problema; así que toda intervención del profesor para señalar errores o sugerir estrategias anula la validación por parte del alumno, quien acepta los juicios del profesor, y por tanto se interrumpe el aprendizaje por adaptación. Es más, los alumnos buscarán obtener del profesor informaciones que les permitan resolver el problema sin tener que realizar un razonamiento, o simplemente buscarán confirmación de sus estrategias; por tanto, durante la situación adidáctica, el profesor deberá abstenerse de juzgar (con palabras o con gestos) el trabajo del alumno, de intervenir voluntariamente o por solicitud del alumno para corregir su trabajo o para sugerir una estrategia de solución. Por el contrario, deberá animar a los alumnos a poner en práctica sus propias estrategias y a validarlas o invalidarlas en la interacción con el medio.

Ante la solicitud de ayuda por parte de los alumnos, el profesor debe devolverles sus preguntas, diciéndoles por ejemplo: ¿tú qué piensas?; ¿qué estás tratando de hacer?; o, intenta hacer lo que estás pensando. Esta solicitud de "abstenerse de actuar" no significa que el profesor esté ausente durante la situación adidáctica; antes bien, está presente al observar las acciones de los alumnos y verificando que la interacción con el medio se desarrolle como fue prevista. En caso de que el alumno abandone el problema ("yo no puedo hacerlo"), el profesor debe intervenir para relanzar el problema: debe hacer caer en cuenta al alumno que puede realizar acciones sobre el medio y hacerle tomar conciencia de las retroacciones del mismo.

\subsubsection{Cabri como medio idóneo para el aprendizaje de la geometría ${ }^{2}$}

De acuerdo con todo lo anterior, para que una situación adidáctica pueda ser utilizada para la enseñanza de un saber determinado, el conocimiento producido por la interacción con el medio debe tener una relación con el saber a enseñar. Es más, para que el profesor pueda abstenerse de intervenir para señalar los errores, debe tener confianza en que el medio generará las

2 En el Proyecto Institucional de Uso de la Geometría Dinámica decidimos utilizar el software Cabri II plus, que fue entregado por el Ministerio de Educación Nacional. Por eso hacemos referencia a dicho software como medio de interacción. Existen otros software de geometría dinámica que podrían emplearse para el trabajo de clase. Animamos a los lectores a explorar dichos software y a adaptar a los mismos los diseños que presentamos aquí. 
retroacciones necesarias para que el alumno mismo encuentre sus errores. El medio es entonces un elemento determinante del aprendizaje por adaptación.

Si consideramos el software Cabri como medio a utilizar en una situación adidáctica, tenemos la garantía de que las retroacciones que ofrecerá a las acciones del sujeto fueron programadas de acuerdo con la teoría de la geometría. Por lo tanto, los conocimientos que produzcan los alumnos en la interacción con Cabri, necesariamente tendrán una relación estrecha con el saber a enseñar (Figura 21).

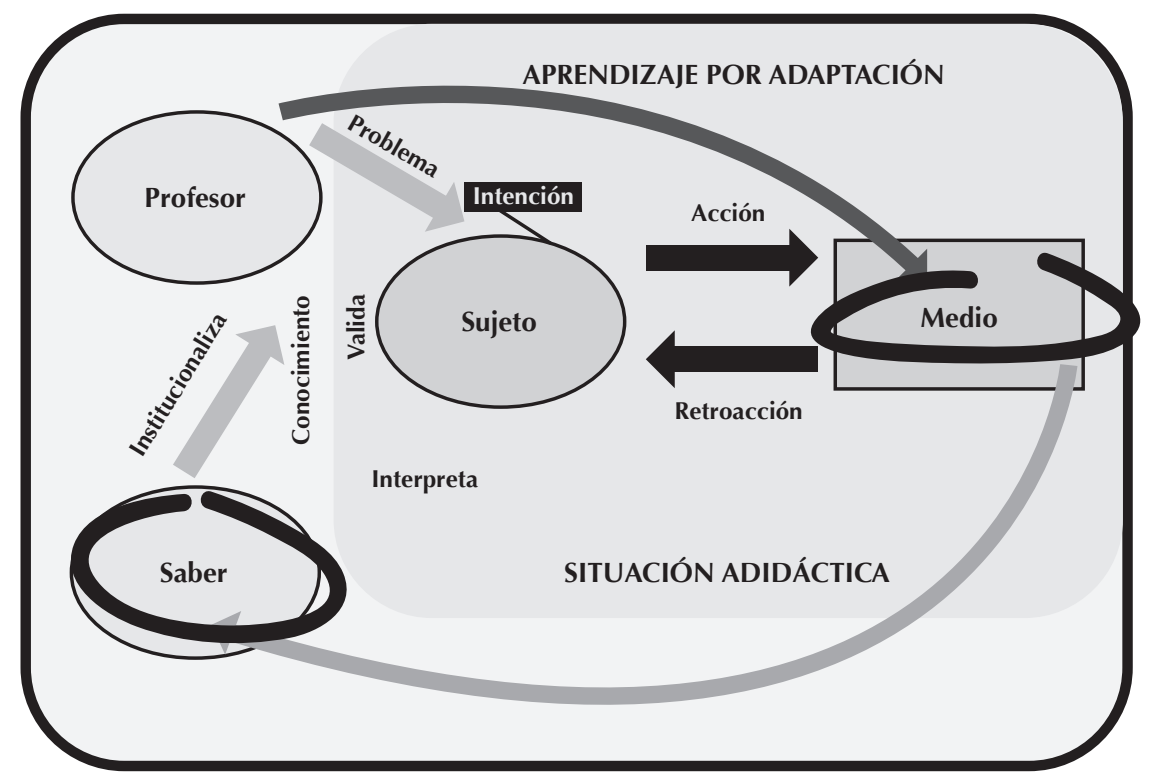

Figura 21. Cabri como medio para el aprendizaje de la geometría

1.5. Implicaciones del marco teórico

Este marco teórico nos propone un modelo de enseñanza:

- El profesor prepara una situación adidáctica; es decir, prepara un problema y un medio,

- Pone en funcionamiento la situación adidáctica: entrega a los alumnos el problema y el medio, y acompaña la interacción de los alumnos con el medio,

- La situación adidáctica conduce a que los alumnos construyan determinados conocimientos que están en relación con el saber a enseñar, 
- El profesor institucionaliza el saber: explicita las relaciones entre ese conocimiento personal y contextualizado con el saber impersonal y descontextualizado.

En este trabajo, consideramos que la responsabilidad de preparar la situación adidáctica no debe recaer sobre el profesor, sino que debe ser asumida por expertos en Didáctica de las Matemáticas. Son ellos quienes preparan el problema y el medio, quienes prevén todas las posibles acciones que realizará el sujeto, y verifican que las retroacciones del medio le permitirán invalidar aquellas acciones incorrectas desde el punto de vista del saber a enseñar, y validar aquellas acciones correctas.

De esta manera, el profesor puede concentrarse en su campo de experticia, que es la gestión de la clase. Así que podemos replantear el modelo de enseñanza de la siguiente manera.

- Los expertos en didáctica diseñan una situación adidáctica.

- El profesor se apropia esa situación adidáctica: comprende los objetivos de la misma, conoce todas las posibles acciones que puede realizar el alumno, las distintas retroacciones del medio a cada una de esas acciones, y los efectos esperados de esas retroacciones; de esta manera prepara su intervención durante la situación adidáctica: tanto sus acciones como sus abstenciones.

- Durante la situación adidáctica observa la interacción de los alumnos con el medio, intentando identificar los comportamientos no previstos en el análisis a priori, clasifica el trabajo de los alumnos según las estrategias previstas en el análisis a priori, e interviene cuando es necesario para relanzar el problema, para señalar las retroacciones del medio, para solicitar que el alumno valide sus procedimientos.

- La situación adidáctica conduce a que los alumnos construyan determinados conocimientos que están en relación con el saber a enseñar.

- Después de la situación adidáctica, el profesor organiza una puesta en común durante la cual a la vez promueve la participación de todos los alumnos, y verifica que hayan construido los conocimientos que se esperaba durante la situación adidáctica.

- Finalmente, institucionaliza el saber, poniéndolo en relación con los conocimientos construidos durante la(s) situación(es) adidáctica(s).

\subsubsection{Importancia de la puesta en común}

La puesta en común obedece a dos grandes tipos de objetivos: socioafectivos y didácticos. Dentro de los objetivos socioafectivos está lograr un ambiente 
de respeto, de debate; el profesor debe establecer y recordar unas normas de comportamiento: Todos tienen derecho a compartir lo que hicieron, mientras alguien habla los demás deben escucharlo con atención, sin burlarse. Todos deben sentirse valorados en lo mucho o poco que lograron hacer. Por eso es importante que el profesor prepare la puesta en común, e identifique los alumnos que más avanzan y aquellos que menos avanzan, pues en la puesta en común deberá darle la palabra primero a los que menos avanzaron y de último a los que más avanzaron.

Por otra parte, el objetivo didáctico de la puesta en común es verificar que todos los alumnos hayan identificado los fenómenos visuales que se esperaba que constataran gracias a la manipulación de las figuras. El profesor debe preparar preguntas que le permitan hacer esa verificación, y asegurarse de que todos los alumnos entienden de qué se está hablando. En el caso que los alumnos no hayan identificado alguno de los fenómenos, podrá proyectar la actividad correspondiente y solicitar a algún alumno que la haga delante del grupo, guiando la identificación del fenómeno en cuestión.

Un comportamiento que el profesor debe evitar especialmente durante la puesta en común, es privilegiar la intervención de los alumnos más aventajados del curso, quienes responderán correctamente todas las preguntas, y darán la impresión de que todo quedó perfectamente comprendido. Esta situación conduce a ignorar los errores de comprensión que pueden surgir durante las actividades, o incluso la ausencia total de comprensión, pues los demás alumnos tratarán de imitar el discurso de los "buenos", sin comprender el por qué.

Por el contrario, lo que se busca es que todos los alumnos, aventajados o no, expongan su trabajo, correcto o no, y que este sea valorado, y sometido a la opinión de los demás. El profesor debe estar atento a la construcción conceptual de todos los alumnos, en especial aquellos que no son aventajados.

Durante la puesta en común, si un alumno expone afirmaciones erróneas, es importante la manera como el profesor interviene; si inmediatamente impone su autoridad para señalar el error, no necesariamente produce comprensión en los alumnos equivocados; más bien, debería someter a debate las afirmaciones, dejando que otros alumnos discutan la veracidad o falsedad de las mismas, o confrontar esas afirmaciones con la observación de fenómenos en la pantalla, mostrando contraejemplos de las afirmaciones, de manera que sean los mismos alumnos los que concluyan sobre sus equivocaciones. En el caso en que identifique que solo muy pocos alumnos han logrado construir el conocimiento buscado, no debe dudar en reiniciar el trabajo individual o en pequeños grupos. 


\subsubsection{Sobre las actividades con lápiz y papel}

En sus inicios, el proyecto no tenía previsto alternar actividades en el computador y actividades con papel y lápiz. En especial, no creemos que sea necesario desarrollar habilidades de construcción tanto con el software como con herramientas clásicas (regla, escuadra o compás). Sin embargo, los profesores participantes en el proyecto insistieron en la necesidad de que los alumnos consignaran su trabajo en los cuadernos como una forma de mantenerlos ocupados, atentos al trabajo de los demás, y de recabar evidencias del trabajo realizado.

En efecto, como en algunos casos deben trabajar tres alumnos con un solo computador o calculadora, los alumnos que no tienen acceso al control del equipo tienden a desinteresarse por el trabajo. Si se les exige entregar un informe escrito del trabajo grupal, deberán prestar atención a la manipulación que realizan sus compañeros, y a lo que sucede en la pantalla. Estos registros escritos del trabajo de los alumnos pueden ser usados como evidencia de su trabajo con fines de evaluaciones formativas o sumativas.

Por ejemplo, las representaciones que hacen los alumnos en sus cuadernos pueden ser fuente de información sobre los fenómenos o propiedades que identifican o no en las figuras de la pantalla del computador. Por otra parte, el hecho de tener que representar los procesos en el papel puede verse como un proceso de descontextualización que contribuye a la construcción de conceptos.

\subsubsection{Los dos tipos de actividad}

Aunque, según el modelo teórico expuesto, en general, el profesor debe abstenerse de comunicar a los alumnos la solución de los problemas durante la situación adidáctica, esto no siempre es posible. Por tanto distinguimos dos tipos de actividad:

- En las Actividades de tipo I, se espera que el alumno invalide las estrategias perdedoras y encuentre una estrategia ganadora.

- En las Actividades de tipo II, se espera que el alumno invalide las estrategias perdedoras pero no que encuentre una estrategia ganadora: únicamente que identifique una dificultad. El profesor puede sugerir la estrategia ganadora como respuesta a esa dificultad. 


\subsubsection{Análisis a priori}

El análisis a priori se aplica a los productos de enseñanza basados en la TSD. Mediante este análisis (los diseñadores de la situación adidáctica) explicitamos los supuestos referidos a los procesos de enseñanza aprendizaje que se generarán en la situación y los resultados que se desean producir: los probables y los seguros.

El objetivo del análisis a priori es permitirle al profesor de matemáticas anticipar los comportamientos de los alumnos durante la actividad, y prever cuándo las retroacciones del medio le permitirán no intervenir para señalar errores, pues los alumnos podrán tomar conciencia de ellos por sí mismos.

Para finalizar, queremos señalar que parte de la justificación de elegir la TSD como marco teórico está en que ofrece herramientas que superan el esquema general de los currículos (objetivos, contenido, metodología y evaluación) lo cual evita que el profesor de matemáticas se centre en los conceptos como único medio para planificar y coordinar su trabajo en el aula; el marco teórico junto con el análisis a priori encausará sus actuaciones hacia la construcción de conocimientos que puedan darle sentido al saber matemático, siendo el alumno el protagonista del proceso. 



\subsection{Ejemplo de enseñanza de transformaciones: Simetría Axial}

Para la enseñanza de la simetría axial proponemos cuatro actividades de clase. Cada actividad está compuesta de series, y en cada una de las series se les pedirá a los estudiantes que realicen tareas específicas. Para cada serie hay un archivo con una figura, hecha en Cabri II plus, sobre la que los estudiantes trabajarán para desarrollar las tareas (los estudiantes no necesariamente deben saber manejar el programa).

La secuencia está planteada para que los alumnos se familiaricen con algunos fenómenos que caracterizan la simetría axial, de modo que esto les permita predecir o anticipar las posiciones de los objetos simétricos, dados ciertos elementos de la simetría. Para que identifiquen el eje, lo ubiquen de manera perceptiva y posteriormente sean capaces de construirlo, y que puedan predecir la posición de una figura simétrica con respecto a otra y a un eje, y construirla.

Además, en cada actividad, las series tienen una secuencia que detallaremos a medida que avancemos. Para ello, analizaremos una a una las actividades, haciendo una descripción, especificando los objetivos, precisando las tareas y lo que esperamos que los estudiantes hagan.

\section{Saber en juego}

Una simetría axial es una transformación geométrica, es decir una correspondencia entre parejas de puntos del plano. Decimos que dos puntos del plano A y $A^{\prime}$ son simétricos con respecto a una recta e (llamada eje de simetría) si y solo si e es mediatriz del segmento $\mathrm{AA}^{\prime}$. Esta condición implica que el segmento $A A^{\prime}$ debe ser perpendicular a e y que e debe pasar por el punto medio de $\mathrm{AA}^{\prime}$. También se deduce que $\mathrm{A}$ y $\mathrm{A}^{\prime}$ deben quedar en semiplanos opuestos con respecto a e. 


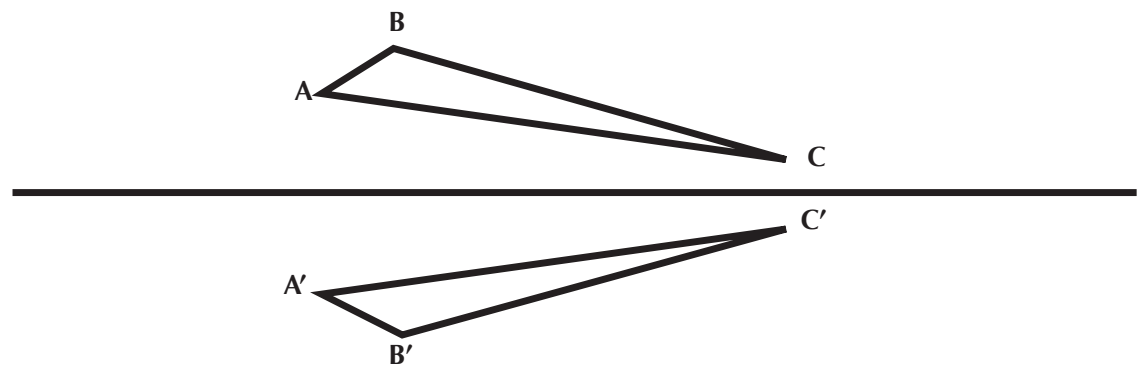

Figura 22. Triángulo $A B C$ y su simétrico $C^{\prime} B^{\prime} A^{\prime}$

Por tanto, si dos figuras (por ejemplo, polígonos) son simétricas con respecto a e, deben tener orientaciones contrarias con respecto a e, ya que la distancia de cada punto a e debe ser igual a la distancia de su homólogo a e. Como se aprecia en la Figura 22, una simetría axial es una isometría, puesto que conserva la forma y el tamaño de las figuras; es decir, si dos figuras son simétricas con respecto a un eje, entonces son congruentes.

\section{ACTIVIDAD 1}

\section{Objetivo}

La finalidad de esta actividad es que los alumnos se familiaricen con algunos fenómenos visuales concernientes al movimiento de figuras simétricas, tales como la dependencia de una con respecto a la otra, los movimientos contrarios con respecto del eje (los alumnos podrían asimilarlo como un espejo imaginario). Esto implica que logren identificar el eje de simetría y predecir su ubicación.

\section{Descripción del medio}

Para esta actividad se trabaja con 12 figuras (Figura 23), en cada una de las cuales hay seis triángulos simétricos (tres negros y tres grises) con respecto a un eje oculto. Los tres triángulos negros tienen diferentes formas, cada triángulo gris es congruente con un triángulo negro. 


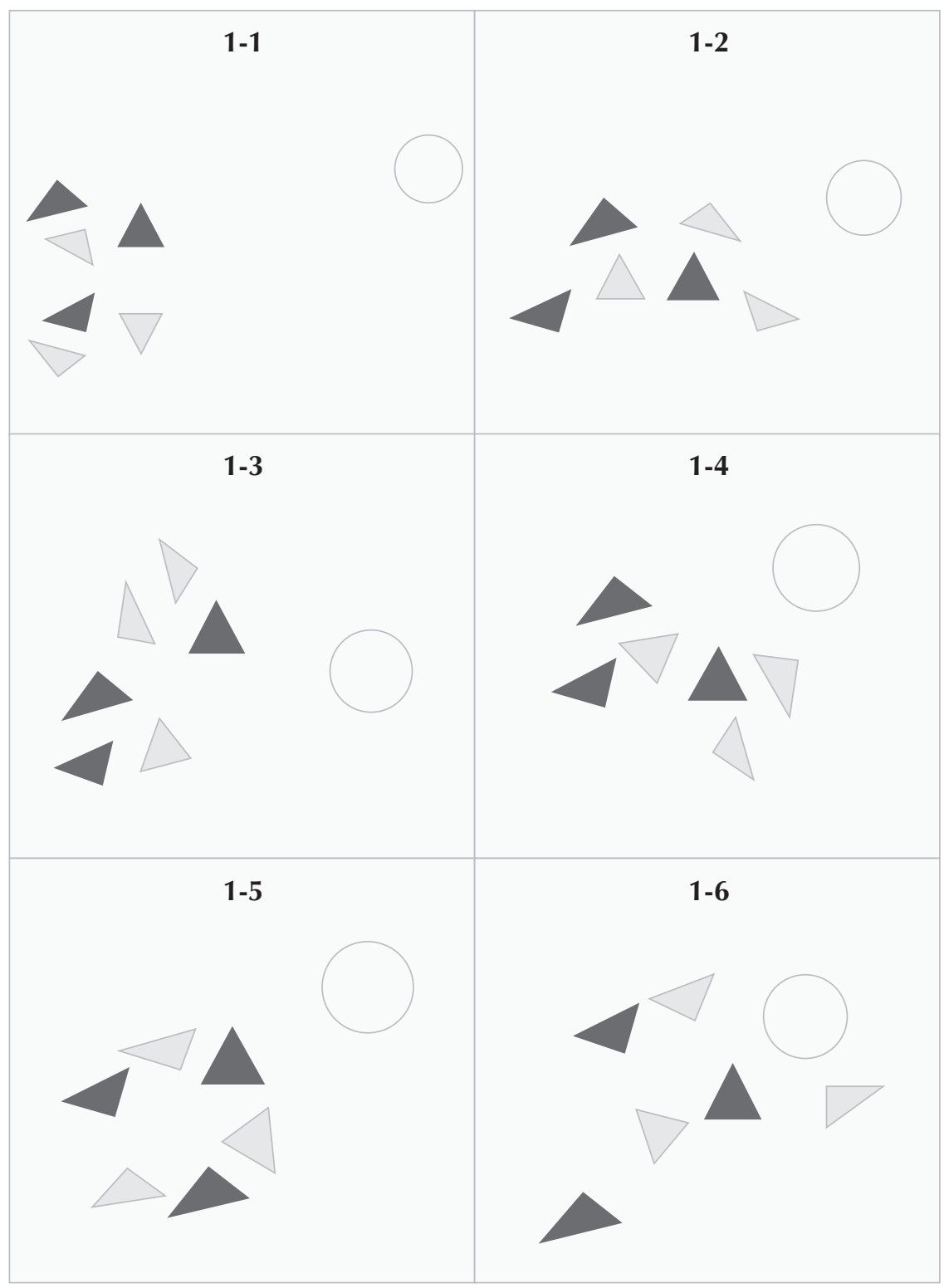

Figura 23. Juego de triángulos con un círculo

En las figuras numeradas 1-1 a 1-6, aparece un círculo. En las figuras numeradas 1-1a a 1-6a (Figura 24) aparecen tres círculos cada uno con un punto sobre este. La diferencia entre las seis series es la orientación (inclinación) del eje. 


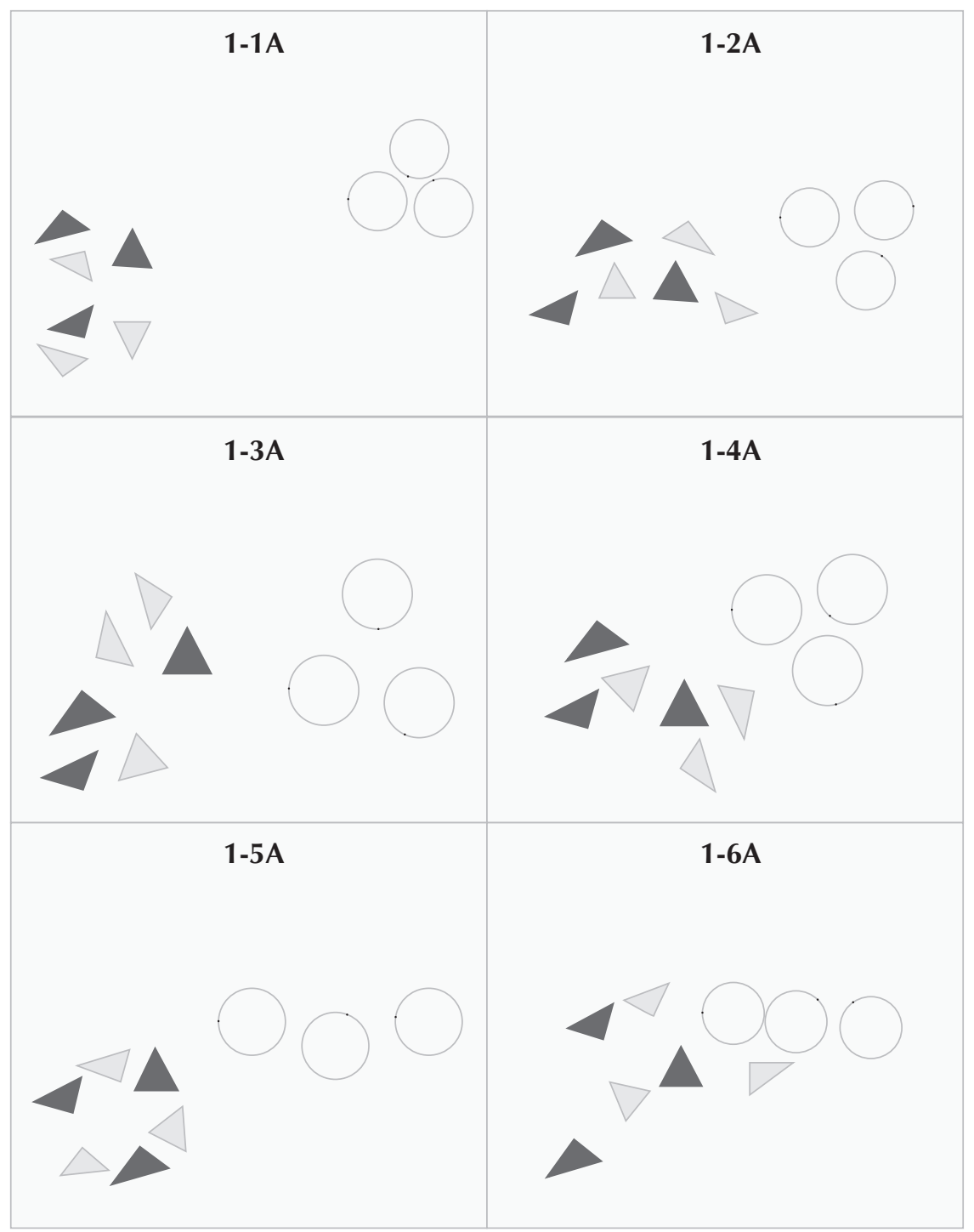

Figura 24. Juego de triángulos con tres círculos

De acuerdo con las características del software, los triángulos grises no se pueden arrastrar directamente dada la dependencia de éstos con respecto a los negros, lo cual no es una propiedad específica de la simetría, sino una particularidad del software; pero los triángulos negros sí se pueden arrastrar, permitiendo llevarlos libremente a cualquier lugar de la pantalla sin que cambien su forma y tamaño, para ello basta hacer clic sostenido sobre el triángulo y arrastrar. 
Adicionalmente, al arrastrar los triángulos negros, los grises se mueven de manera que conservan la simetría. Del mismo modo, los círculos de las series 1-1 a 1-6 no se pueden arrastrar, mientras que los de las series 1-1a a 1-6a se pueden mover libremente agarrándolos por el punto que aparece sobre ellos. Cabe notar que en todas las series, la única herramienta de Cabri disponible es el apuntador.

\section{Descripción de la actividad}

Se quiere que los alumnos descubran los siguientes fenómenos visuales:

- Si dos figuras son simétricas, una depende de la otra. Es decir, una podrá arrastrarse directamente en la pantalla, pero la otra no, sin embargo se moverá cuando la primera se mueva. En particular, se quiere que los alumnos descubran que los triángulos grises no se pueden arrastrar y los negros sí, y que al arrastrar uno negro se mueve uno gris.

- Si dos figuras son simétricas, tienen movimientos contrarios con respecto al eje de simetría. En concreto se quiere que los alumnos descubran que un triángulo negro y el gris correspondiente tienen movimientos contrarios con respecto al eje se simetría.

- Si dos figuras son simétricas, se tocan en el eje de simetría. Específicamente, se quiere que los alumnos descubran que hay lugares en los que el triángulo negro se superpone con el gris (su simétrico).

- Dos figuras simétricas coinciden a lo largo de una recta llamada eje de simetría. Queremos que los alumnos constaten que las distintas posiciones en las que se superponen un triángulo negro y su simétrico están a lo largo de una recta.

Para alcanzar los objetivos propuestos, y para que los alumnos identifiquen esos fenómenos visuales y se familiaricen con ellos, se les pedirá que realicen cuatro tareas.

\section{Tareas de la actividad}

\section{Primera tarea}

\section{Llevar los triángulos negros dentro del círculo}

El propósito de esta tarea es que los alumnos usen el arrastre para tratar de mover los triángulos. Se espera que agarren los triángulos negros directamente y los metan dentro del círculo. No deberían tener ninguna dificultad para hacerlo. 
Al desplazar los triángulos negros, se darán cuenta de que los grises también se mueven, y que en algún momento se superponen con los negros. Es de suma importancia que los alumnos descubran por sí solos cómo funciona la figura, de modo que el profesor debe limitar sus intervenciones, es decir, solo intervendrá para evitar que los estudiantes abandonen la tarea o para recordar la misma.

\section{Segunda tarea}

\section{Llevar los triángulos grises dentro del círculo}

El propósito de esta tarea es que los alumnos usen el arrastre para tratar de mover los triángulos. Se espera que intenten agarrar los triángulos grises directamente y no puedan moverlos. Si los alumnos dicen que no es posible mover los triángulos grises, el profesor puede hacerles caer en cuenta que la posición inicial de esos triángulos no es la actual, por lo tanto sí se mueven. Se espera que los alumnos caigan en la cuenta que al mover los negros se mueven los grises. El profesor solo debe intervenir para evitar que los estudiantes abandonen la tarea o para recordar la misma.

Al darse cuenta los alumnos de que los triángulos grises no se dejan arrastrar, deberían cambiar de acción e intentar arrastrar los otros triángulos. Si no lo hacen espontáneamente, el profesor puede intervenir.

De acuerdo con el análisis hecho, el desarrollo de esta tarea genera un aprendizaje por adaptación en el alumno puesto que si decide arrastrar los triángulos grises el medio no lo dejará y tendrá que cambiar de estrategia. En cambio, si decide arrastrar los triángulos negros podrá resolver la tarea. Al arrastrar los triángulos negros constatará que el movimiento de los grises depende del de los negros que es el objetivo de la actividad.

\section{Tercera tarea}

\section{Llevar todos los triángulos dentro del círculo}

El objetivo es que los alumnos confirmen que los movimientos de un triángulo y su simétrico son contrarios e intenten argumentar que es imposible ejecutar la tarea.

Esta vez los alumnos se percatan de que los triángulos solo se unen en algunos sitios de la pantalla, y que allí debería estar ubicado el círculo. Pero por no darse estas condiciones, la tarea es imposible. 
Es posible que los alumnos vuelvan a arrastrar los triángulos negros dentro del círculo, constatando que los grises quedan por fuera. También pueden juntar todos los triángulos en algún punto de la pantalla, y luego intenten arrastrar el círculo hasta ese punto, pero no podrán arrastrar el círculo.

Como resultado de llevar a cabo estas acciones previstas, los alumnos descubren que si se meten los triángulos negros en el círculo, los grises quedan por fuera; y en caso de querer meter los grises, es necesario sacar los negros. Pero mientras se realizan estas acciones, se evidencia que al arrastrar un triángulo negro en algunas direcciones, el gris correspondiente se mueve en sentido contrario. En particular, estando en la figura 1 donde el eje de simetría (oculto) es horizontal, al mover el triángulo negro hacia arriba el gris se mueve hacia abajo, y viceversa. Lo cual implica que el aprendizaje por adaptación producto de concluir la tarea, corresponde con el propósito de la misma.

Aquí es importante que el profesor solicite a los alumnos que justifiquen por qué no es posible realizar la tarea. Se espera que den justificaciones como las siguientes: "si meto los negros se salen los grises", "los triángulos grises y los negro se mueven en sentidos opuestos", "el círculo no está en el lugar donde se juntan los triángulos". De esta manera los alumnos comienzan a verbalizar las características que se pretende que observen.

\section{Cuarta tarea (con la serie 1-1a)}

\section{Poner los tres círculos en algún lugar de la pantalla donde puedan ponerse todos los triángulos dentro de ellos (sucesivamente).}

La intención es que los alumnos se percaten de que los círculos deben ubicarse a lo largo de una recta (por eso se utilizan tres círculos), y el profesor debe asegurarse de que los alumnos son conscientes de que hay más posiciones en las que se pueden ubicar los círculos. También debe asegurarse de que en cada círculo pueden meterse todos los triángulos.

Se espera que los alumnos arrastren un triángulo negro para juntarlo con su pareja en algún lugar, dado que en la actividad anterior se percataron de que un triángulo y su pareja se unen en algunos sitios de la pantalla; de esta manera podrán mover uno de los círculos a esa posición, quedando un triángulo y su simétrico dentro de él. Luego se esperaría que hagan lo mismo para meter las dos parejas de triángulos restantes en los otros dos círculos. 
Es posible que algunos alumnos junten parejas de triángulos que no son simétricos, obteniendo una configuración de los círculos diferente a una línea recta. En ese caso, el profesor debe solicitar a los alumnos meter todos los triángulos dentro de cada uno de los círculos, tal como lo pedía la tarea. Cuando intenten meterlos todos se darán cuenta que no es posible, pues al introducir uno negro su simétrico se alejará del círculo.

Nuevamente el aprendizaje por adaptación producto de efectuar las posibles acciones termina siendo que las parejas de triángulos solo se unen a lo largo de una recta, y que además no hay otras posiciones donde suceda esto. Ello implica que la única manera de concluir la tarea es percatándose de la presencia del eje de simetría, que es en últimas lo que se quiere.

Es importante que el profesor solicite a los alumnos que han terminado la tarea que efectivamente metan todos los triángulos sucesivamente en cada uno de los círculos. Además, debe preguntarles: ¿Si tuvieras más círculos dónde podrías colocarlos de manera que puedan meterse todos los triángulos? Se espera que los alumnos hagan una referencia verbal o un gesto que indica una línea recta.

\section{Análisis a priori de la secuencia de tareas}

En general en cada una de las cuatro actividades, cuando los alumnos avancen de una serie a otra, esperamos que renuncien a las acciones que anteriormente no les han permitido lograr sus intenciones, y que refuercen las que sí. Además, esperamos que tomen conciencia de las diferencias entre una serie y otra.

En esta primera actividad esperamos que los alumnos al pasar de la primera a la segunda serie (o en su defecto, de la segunda a la tercera), no intenten agarrar los triángulos grises sino que arrastren directamente los negros cuando quieran mover los grises. Esto para cada tarea.

\section{Primera y segunda tareas}

Esperamos que tomen conciencia de que en distintas series los movimientos de un triángulo y su pareja tienen diferentes orientaciones. Es decir, que en la primera serie al arrastrar un triángulo negro hacia arriba su pareja se mueve hacia abajo y viceversa, pero al arrastrarlo en dirección horizontal la distancia entre ellos no varía; mientras que en la segunda serie al arrastrar un triángulo negro hacia la derecha su pareja se mueve hacia la izquierda y viceversa, pero al arrastrarlo en dirección vertical la distancia entre ellos no varía. 


\section{Tercera tarea}

Esperamos que al avanzar de una serie a otra demoren menos tiempo intentando meter todos los triángulos en el círculo antes de argumentar que no es posible resolver la tarea, incluso no sería extraño que al pasar de la segunda a la tercera serie o de la tercera a la cuarta argumenten que no es posible resolver la tarea antes de intentar arrastrar los triángulos.

\section{Cuarta tarea}

Esperamos que los alumnos tomen conciencia de que para diferentes series los círculos quedan ubicados en distintas direcciones (horizontal, vertical,...). Sería importante que el profesor solicite a los alumnos dibujar en su cuaderno la posición en que quedaron los círculos en cada serie al terminar la tarea, con el fin de que puedan comparar posteriormente esas posiciones.

\section{Puesta en común}

Es de esperarse que haya grupos de trabajo más adelantados que otros, entonces el profesor puede disponer una puesta en común una vez finalizadas las cuatro tareas con las seis series, con el fin de constatar que los alumnos manifiestan los fenómenos visuales que se pretendía que descubrieran y que de alguna manera se hayan familiarizado con ellos. El profesor pedirá a algunos alumnos que pasen al frente del grupo para que expliquen a los demás cómo desarrollaron las tareas. Es importante que el profesor identifique cuáles grupos terminaron y cuáles no, con el propósito de pasar primero a los grupos más rezagados. También es conveniente que en su mayoría los grupos expongan su trabajo.

Es importante que los alumnos hablen (con sus propias palabras) de la dependencia de los triángulos grises con respecto a los negros, de los movimientos contrarios, de que los triángulos se juntan a lo largo de una línea recta.

\section{Concurso}

Actividad para finalizar. En esta instancia se supone que ya los alumnos están familiarizados con los fenómenos visuales que hemos mencionado anteriormente, pero para ello solo han utilizado estrategias estrictamente perceptivas. El propósito de este concurso es bloquear esas estrategias, y llevar a los alumnos a que utilicen los conocimientos que han adquirido para anticipar la posición del eje de simetría. Por esta razón se impone la condición de "no mover los triángulos antes de determinar la posición de los círculos". 
Para este concurso se organizan equipos competidores dentro del salón de clase (entre seis y ocho alumnos por equipo), el profesor explica que deberán solucionar la cuarta tarea: colocar los círculos donde puedan meterse todos los triángulos dentro de ellos, pero no podrán mover los triángulos antes de colocar los círculos. Para garantizar que los alumnos se comuniquen y se pongan de acuerdo en una estrategia, el profesor explica que él seleccionará un representante de cada equipo para realizar la tarea. Los diferentes equipos deben reunirse para practicar la tarea con las figuras ya trabajadas y ponerse de acuerdo en una estrategia que les permita ganar el concurso.

El profesor debe dar un tiempo prudencial para que los alumnos discutan entre ellos y pongan a prueba las estrategias, y debe asegurarse de que han entendido el concurso, que todos están participando en la discusión y que además de proponer estrategias de solución las ponen a prueba en las figuras ya trabajadas.

Una vez finalizada esta etapa de trabajo en equipo, comienza el concurso. El representante escogido por el profesor deberá ubicar los tres círculos sin mover los triángulos y luego otro alumno, o en su defecto el profesor, moverá los triángulos para comprobar si es posible meter todos los triángulos dentro de cada círculo. Del mismo modo lo harán los representantes de los otros equipos.

En caso de que uno de los representantes no logre resolver la tarea puede repetirse el concurso, y finalmente organizar una puesta en común para que los grupos expongan sus estrategias.

Para resolver la tarea, los alumnos deben identificar cuál es la pareja de cada triángulo (sin moverlos), utilizando la forma y el tamaño, y además identificar los puntos donde se unen, que deben estar sobre el eje de simetría.

Si los alumnos deciden colocar los círculos al azar, será muy poco probable que estos queden alineados sobre el eje de simetría, y al intentar meter todos los triángulos quedarán algunos por fuera.

El profesor deberá preparar figuras para el concurso, diferentes a las de las series trabajadas, de manera que los alumnos no puedan resolver el problema únicamente recordando la posición de los círculos.

Los alumnos siempre tienen la posibilidad de invalidar las estrategias perdedoras gracias a las retroacciones del medio, y de darse cuenta que la estrategia ganadora consiste en identificar las parejas de triángulos simétricos 
para anticipar la posición del eje de simetría y ubicar los círculos sobre este eje ya que, de la tarea tres, ellos han descubierto que un objeto y su simétrico se superponen sobre el eje de simetría.

Como consecuencia del concurso, es ineludible que los alumnos intenten anticipar la posición del eje de simetría, al ser esta la única estrategia ganadora porque las demás no permiten concluir la tarea. Además, si todos no han descubierto la estrategia, la puesta en común permite confrontar esta situación, ya que los distintos grupos expondrán la manera como planearon desarrollar la tarea.

En conclusión, como producto del desarrollo de las cuatro tareas de esta primera actividad, los alumnos se darán cuenta de que los triángulos grises dependen de los triángulos negros, que los triángulos grises tienen movimientos contrarios con respecto a una recta que pasa por la mitad entre un triángulo negro y su pareja; que los triángulos negros y los grises tienen orientaciones contrarias con respeto a tal recta; además podrán precisar su ubicación; por último, del concurso lograrán anticipar la posición del eje de simetría sin mover los triángulos.

Es importante que el profesor institucionalice estas conclusiones utilizando las palabras de los propios alumnos, y haga tomar nota de las mismas en el cuaderno.

ACTIVIDAD 2

\section{Objetivos}

1. Además de reforzar la identificación de los fenómenos visuales concernientes al movimiento de figuras simétricas trabajados en la Actividad 1, se busca que los alumnos constaten que las figuras simétricas con respecto a un eje giran en sentidos contrarios.

2. Se busca que los alumnos pasen de una visión global de los triángulos, a considerar sus vértices y lados.

\section{Descripción del medio}

Para el desarrollo de esta actividad, los alumnos trabajarán con seis figuras (Figura 25), en cada una de ellas se presentan tres triángulos congruentes (negro, gris y punteado). 


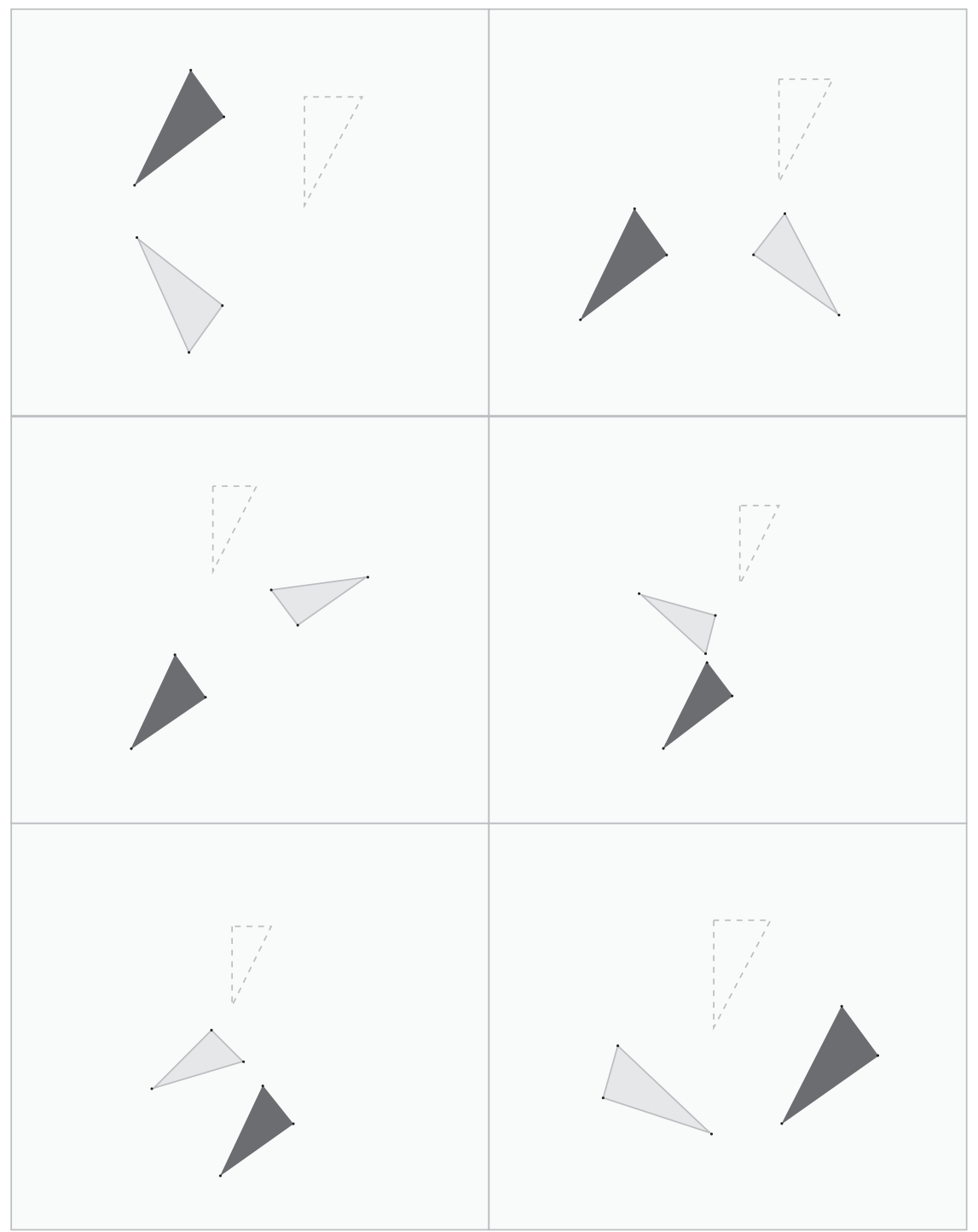

Figura 25. Figuras del medio de la Actividad 2

El gris simétrico del negro con respecto a un eje que permanece oculto y el punteado permanece fijo (no se puede mover) de modo que el gris pueda hacerse coincidir con él. El triángulo negro pude moverse arrastrando dos de sus vértices: uno permite trasladarlo por cualquier lugar de la pantalla y el otro permite girarlo alrededor del primero. El tercer vértice no se deja arrastrar. El triángulo gris no puede arrastrarse, pero se mueve al arrastrar el negro. Al igual que en la actividad 1, la única herramienta de Cabri disponible es el apuntador. 


\section{Descripción de la actividad}

El propósito de esta actividad es que los alumnos descubran los mismos fenómenos visuales de la primera actividad, más el hecho de que si una figura gira en el sentido de las agujas del reloj, su simétrica gira en sentido contrario. Además, que pasen de una percepción global de las figuras a una percepción local; los triángulos no serán únicamente formas globales sino que estarán compuestos por tres vértices y tres segmentos. Para lograr lo anterior, se les pide a los alumnos desarrollar la siguiente tarea.

\section{Tarea}

\section{Superponer el triángulo gris y el triángulo punteado}

Se espera que los alumnos descubran que el triángulo negro se puede mover por dos de sus vértices, teniendo en cuenta que ya saben que para mover el gris deben arrastrar el negro, y esta vez no se moverá igual que en la primera actividad.

También se supone que ellos podrían intentar agarrar el triángulo punteado para Ilevarlo hacia el gris, y este no se dejará arrastrar, entonces llevarán el gris sobre el punteado, pero una vez logrado esto deberán girarlo para hacer que coincidan. Esto último les permitirá descubrir que al girar en sentido horario el negro, el gris lo hará en sentido contrario.

Note que para poder finalizar la tarea es necesario que el alumno descubra que una figura y su simétrica giran en sentidos contrarios, ya que para girar el triángulo gris debe girar el negro, y no hay otra forma de hacerlo. Además, ellos al intentar hacer coincidir los triángulos, se fijarán en los vértices, ya que al girar el triángulo negro sin trasladarlo, un punto de éste y el gris permanecen fijos, mientras los otros dos se giran tanto en el triángulo negro como en el gris, pero en sentidos opuestos. Entonces se concluye que el aprendizaje producto del desarrollo de la actividad corresponde al objetivo propuesto.

\section{Análisis a priori de la secuencia}

A medida que avancen por las seis series se espera que los alumnos abandonen algunas estrategias que no resultan útiles para resolver la tarea. Se espera que al pasar a la segunda serie, no intenten arrastrar el triángulo gris, o arrastrar el triángulo negro tomándolo de un lado, o arrastrar el triángulo punteado. 
Se espera que tomen conciencia de que en cada serie la posición del eje de simetría es diferente (horizontal, vertical y oblicua). Pero es importante que el profesor les pida que dibujen en su cuaderno la posición de los triángulos cuando han terminado la tarea en cada serie, de manera que puedan posteriormente comparar esas distintas posiciones.

También es importante en esta actividad que ellos comiencen a manipular los triángulos arrastrando sus vértices, y constaten que hay una correspondencia entre los vértices del triángulo negro y los del triángulo gris. Es decir, que ya no solo conciben los triángulos como figuras globales, sino como compuestos por líneas y puntos. Todos estos elementos deberían ser nombrados en una puesta en común al terminar toda la actividad.

\section{ACTIVIDAD 3}

\section{Objetivos}

En las actividades 1 y 2 los alumnos han aprendido a predecir la posición del eje de simetría de manera aproximada, esta vez se quiere que precisen esa posición. Más concretamente, que argumenten que el eje de simetría pasa por los puntos medios de los puntos simétricos, de modo que puedan construir el eje haciendo uso de herramientas geométricas.

\section{Descripción del medio}

Para el desarrollo de esta actividad se usan siete figuras (Figura 26).

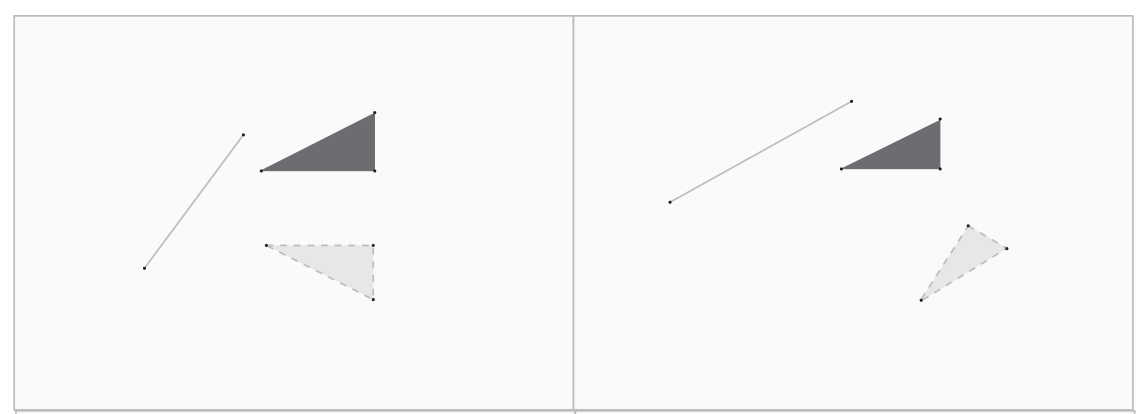




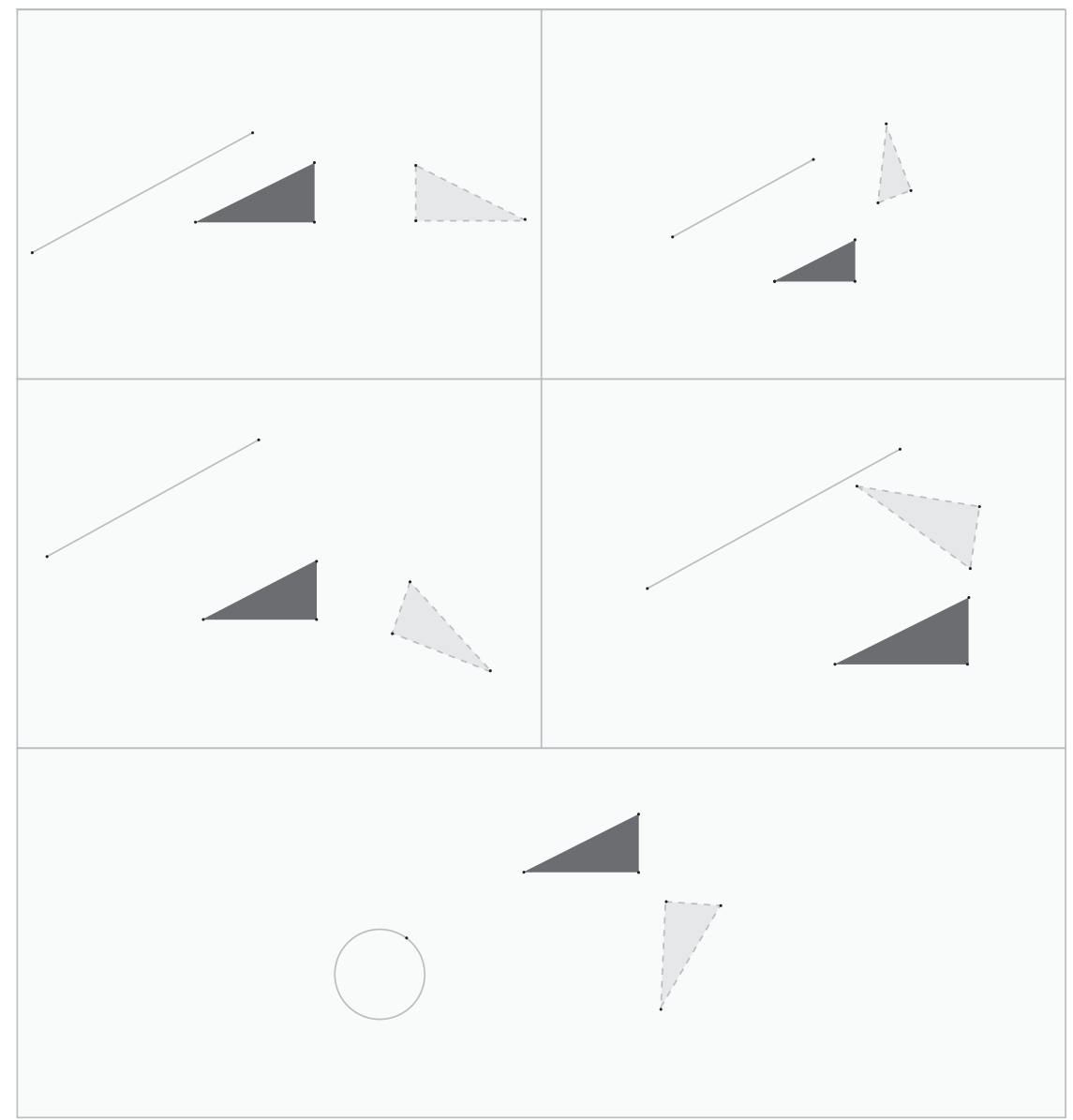

Figura 26. Figuras del medio de la Actividad 3

En las series 1 a 6 la única herramienta Cabri disponible es el apuntador, en la serie siete todas las herramientas están disponibles. En las seis primeras se presenta un triángulo negro, uno gris y un segmento. El triángulo gris es simétrico del negro con respecto a un eje que permanece oculto, por tanto, no se deja arrastrar. El triángulo negro se deja arrastrar por dos de sus vértices; uno permite trasladarlo y el otro rotarlo, de modo que no cambia su forma ni tamaño. El segmento puede desplazarse arrastrándolo directamente o arrastrando sus puntos extremos. Cuando el segmento coincida aproximadamente con el eje de simetría, aparecerá en la pantalla un punto con el letrero ¡Muy bien! 
La diferencia entre cada una de las seis primeras figuras es la inclinación del eje. En la séptima figura se presenta un triángulo gris, uno negro y un círculo con un punto sobre él. El triángulo negro se deja arrastrar por dos de sus vértices; uno permite trasladarlo y el otro rotarlo, de modo que no cambia su forma ni tamaño mientras el gris se mueve de modo que conserva la simetría. El círculo funciona como interruptor al mover el punto para cambiar la pendiente del eje de simetría.

\section{Descripción de la actividad}

Al trabajar con las seis primeras figuras se quiere que los alumnos comprendan que el eje de simetría debe ubicarse de modo que pase por los puntos medios de puntos simétricos; esto puede ser manifestado por los alumnos con frases como "el espejo debe quedar en la mitad de los triángulos" o aún más preciso, "el segmento debe quedar en la mitad entre este punto y este punto (señalando dos puntos simétricos)". Para ello se les pide que realicen dos tareas.

\section{Primera tarea (en las seis primeras figuras)}

\section{Mover el segmento hasta que represente el espejo entre el triángulo negro y el gris.}

Se espera que en las actividades anteriores los alumnos hayan hecho referencia espontáneamente a un espejo, diciendo que los triángulos grises parecen imagen de los negros con respecto a un espejo. Si no lo han hecho, el profesor podrá hacer esta referencia para poder referirse al segmento como representación de un espejo.

En esta tarea, se espera que los alumnos lleven el segmento a la posición en la que ellos creen que debe ubicarse el espejo. Logrado esto con cierta precisión, debe aparecerles un punto con un letrero que dice: “¡Muy bien!”. Por ejemplo en el caso de la primera figura (Figura 27):

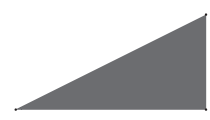

Muy bien!

Figura 27. Estrategia 1 
Es importante que los alumnos descubran que pueden arrastrar el segmento tomándolo de la línea y en ese caso se desplaza sin cambiar su inclinación ni su tamaño, o pueden arrastrarlo de uno de sus extremos, cambiando así su tamaño e inclinación. Si el profesor observa que solo utilizan una de estas dos formas de arrastre, puede sugerirles que utilicen la otra.

Es posible que algunos alumnos utilicen una de las siguientes estrategias para solucionar la tarea:

- Mover el triángulo negro hasta que se cruce con el triángulo gris y hacer que el segmento pase por los puntos de intersección (Figura 28).

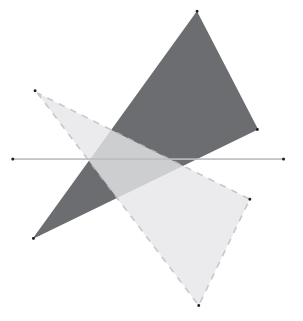

\section{Muy bien!}

Figura 28. Estrategia 2

- Mover el triángulo negro hasta que uno de sus lados coincida con el lado correspondiente del triángulo gris y hacer que el segmento pase por ese lado (Figura 29).

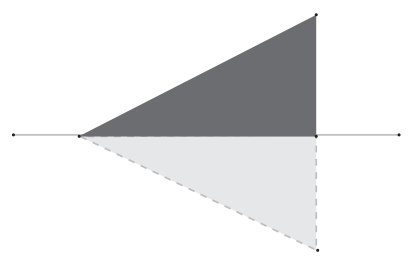

\section{Muy bien!}

Figura 29. Estrategia 3

Estas estrategias son correctas, pero el profesor deberá pedirles a estos alumnos que intenten resolver el problema sin mover los triángulos, a fin de que utilicen las relaciones entre los puntos simétricos y el eje.

Es posible que algunos alumnos renuncien a anticipar la posición correcta del segmento, y se limiten a mover al azar dicho segmento, hasta que vean 
aparecer el letrero "¡Muy bien!". En este caso el profesor debe intervenir y hacerles caer en la cuenta de que se trata de encontrar una estrategia para resolver el problema, gracias a lo que han aprendido en las actividades anteriores y no solamente de lograr que aparezca el letrero.

También es posible que algunos alumnos se limiten a colocar el segmento más o menos en la mitad del espacio entre los dos triángulos, y no logren encontrar la posición correcta de esta manera. En este caso, el profesor deberá intervenir para hacer centrar su atención no en los triángulos de manera global, sino en los vértices correspondientes.

Como producto de la interacción con las figuras los alumnos comprenden que el segmento debe ubicarse en la mitad de la distancia entre puntos correspondientes, lo que es el propósito de esta tarea. Al terminar estas seis series debe realizarse una puesta en común para presentar las diferentes estrategias y concluir sobre esta última. Al terminar la puesta en común se introduce la segunda tarea de esta actividad, como se explica a continuación.

\section{Segunda tarea (en la séptima figura)}

\section{Construir un segmento de modo que represente el espejo que refleja el triángulo negro en el triángulo gris}

En esta tarea se introducirá por primera vez el arrastre para validar una construcción, invalidando las estrategias de ajuste perceptivo de las figuras. Este cambio en el contrato didáctico no será fácilmente comprendido o aceptado por los alumnos. Por eso es necesario que el profesor lo "ponga en escena", delante de todo el grupo, para convencerlos mediante un ejemplo:

Una vez terminada la primera tarea con las seis figuras iniciales, el profesor organizará una puesta en común para resaltar las condiciones que debe cumplir el segmento para que represente el "espejo" entre el triángulo negro y el gris. Se espera que en esa puesta en común se llegue al acuerdo de que la estrategia para obtener el "muy bien" debe ser poner el segmento de manera que pase por la mitad entre cada pareja de puntos correspondientes de los dos triángulos. Luego mostrará la séptima figura, pasará a un estudiante al frente y planteará la tarea: debe construir el segmento que represente el espejo que refleja el triángulo negro en el triángulo gris.

Se espera que inicialmente el alumno se pregunte cómo construir el segmento, de modo que el profesor debe intervenir para orientar el manejo de la herramienta "segmento", dado que es la primera vez que se les pide que construyan. El alumno construirá el segmento en cualquier parte de la 
pantalla y lo arrastrará para ubicarlo entre los dos triángulos, buscando que represente el espejo entre los dos triángulos. Una vez el alumno ha ajustado perceptivamente el segmento, el profesor explicará que en esta figura no sale el letrero "¡Muy bien!" y que por tanto se necesita otra forma de verificar si el segmento está correctamente colocado; mostrará la herramienta "simetría axial" para construir el triángulo simétrico del negro con respecto al segmento que el alumno ha construido perceptivamente. Pueden presentarse dos situaciones:

- El triángulo construido (negro) no coincide con el triángulo gris, lo cual indicaría que el segmento quedó mal construido. Entonces el alumno buscará acomodar el segmento hasta que los triángulos coincidan completamente (Figura 30).

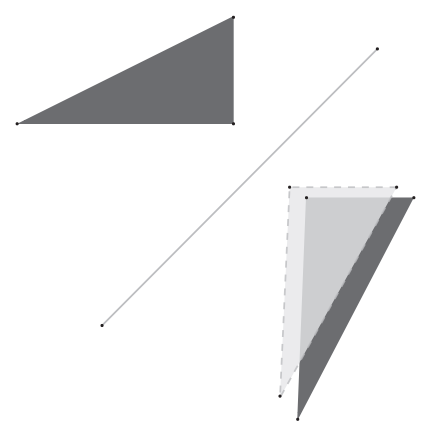

Figura 30. Estrategia 4

- El triángulo construido (negro) coincide con el triángulo gris, lo cual indicaría que el segmento quedó "bien ubicado" (Figura 31).

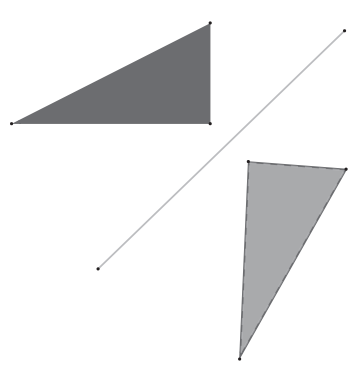

Figura 31. Estrategia 5 
Una vez validada esta tarea perceptiva, el profesor pedirá al alumno que mueva el punto sobre el círculo y esto provocará la siguiente situación (Figura 32):

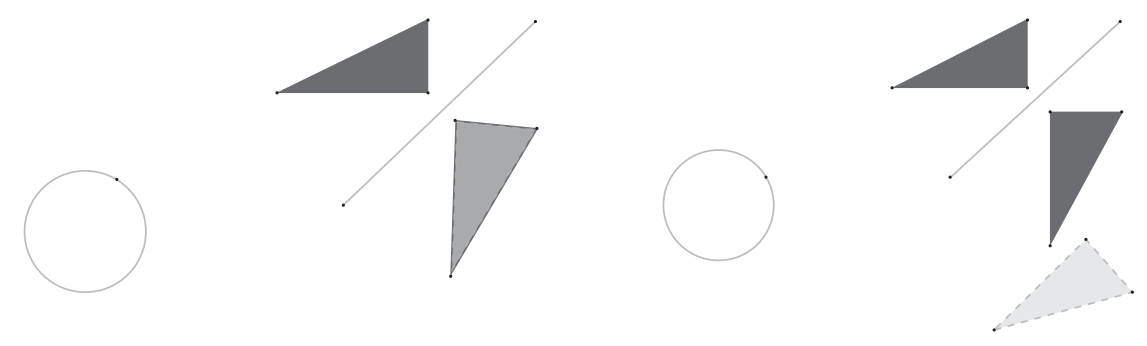

Figura 32. Resultado del movimiento del punto sobre el círculo

Al mover el punto sobre el círculo el eje de simetría (oculto) cambia de pendiente, provocando el cambio de posición del triángulo gris, y queda en evidencia que el espejo queda mal ubicado; el profesor explicará que ahora se trata de construir un segmento que siempre sea el espejo entre los dos triángulos, aunque el triángulo gris se mueva.

Una vez que se ha invalidado la estrategia de ajuste perceptivo mediante el arrastre, finaliza la puesta en común y cada pareja debe intentar resolver el problema.

Esta actividad es de tipo II según nuestro marco teórico. Es decir, sirve para invalidar las estrategias perceptivas de los alumnos, pero no se espera que ellos encuentren una estrategia ganadora. Solamente se espera que formulen de manera suficientemente precisa el problema al que se enfrentan y la necesidad que tienen para resolverlo. En el momento que los alumnos manifiesten que necesitan crear un punto que siempre esté en la mitad de dos puntos correspondientes, el profesor debe intervenir para mostrarles la herramienta "punto medio" y enseñarles a usarla.

De esta manera la herramienta "punto medio" se convierte en la respuesta a una necesidad de los alumnos. Es importante que ellos experimenten el uso de dicha herramienta, que midan (con la regla o con la herramienta "distancia" de Cabri) las distancias del punto medio a los dos puntos de referencia, y que arrastren los puntos para constatar que independientemente de la posición de los puntos, el punto medio siempre está en la mitad de los otros dos. 
Es posible que algunos alumnos formulen el problema como que se necesita que el segmento se mueva al mismo tiempo que el triángulo, e incluso intenten utilizar el punto sobre el círculo para construir el segmento. Esta formulación no es suficiente, pues no hace referencia a la propiedad que se quiere introducir. El profesor deberá intervenir con preguntas sobre cómo se acordó en la puesta en común que es la estrategia para ubicar correctamente el espejo, de manera que los alumnos vuelvan a hacer referencia a una posición a igual distancia de los dos triángulos.

Los alumnos después de ensayar estrategias perceptivas e invalidarlas, harán la pregunta que se espera que se planteen: ¿cómo hacer para que el segmento quede en la mitad de la distancia entre puntos correspondientes, aún después de mover el interruptor? En ese momento el profesor interviene para indicarles cómo usar la herramienta "punto medio".

Es necesario que los alumnos experimenten con la herramienta señalada en un archivo aparte, y luego la utilicen para resolver la tarea realizando las dos validaciones (estática y dinámica). Debe terminar la actividad con una corta puesta en común y una institucionalización del concepto de "punto medio" como un punto que siempre está en la mitad de otros dos, sin importar cómo se muevan esos puntos, y el hecho de que para lograr que un punto siempre esté en la mitad entre otros dos debe usarse la herramienta "punto medio".

Como preparación para la cuarta actividad es necesario que los alumnos construyan los segmentos entre puntos correspondientes de los dos triángulos, a fin de que constaten que esos segmentos son paralelos entre sí y perpendiculares al eje de simetría. Sin embargo, no es necesario que formulen estas propiedades.

\section{ACTIVIDAD 4}

\section{Objetivos}

El propósito de esta actividad es precisar las condiciones para construir la imagen de una figura con respecto a un eje de simetría. Específicamente, que los alumnos comprendan que un punto y su imagen quedan sobre una recta perpendicular al eje de simetría y a igual distancia de dicho eje, pero en semiplanos diferentes. 


\section{Descripción del medio}

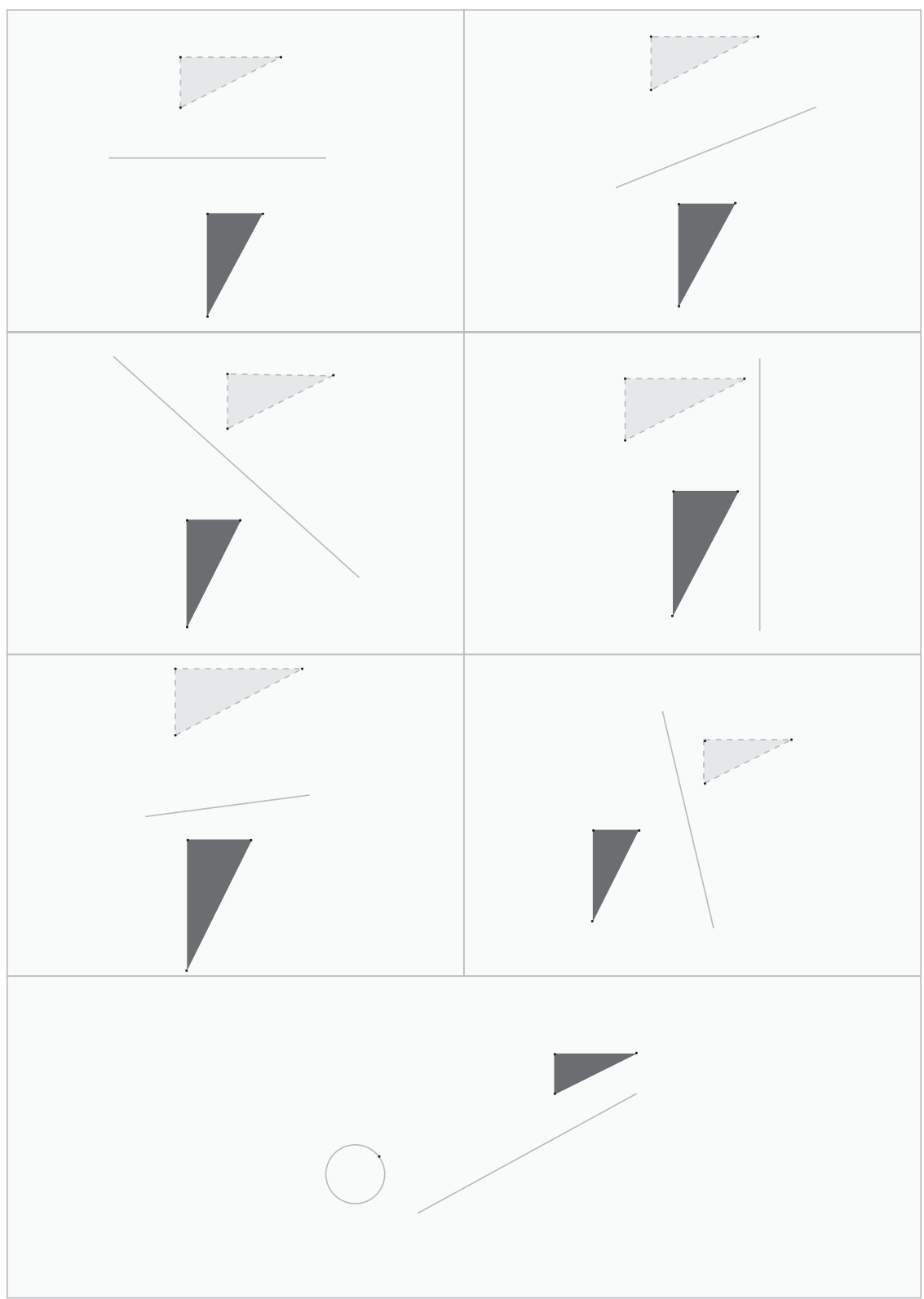

Figura 33. Figuras del medio de la Actividad 4

Como se aprecia en la Figura 33, para el desarrollo de esta actividad se trabaja con siete figuras. En las seis primeras se presenta un triángulo ne- 
gro, uno gris y una recta. El triángulo negro se deja arrastrar por un solo vértice, y no puede girarse. El triángulo gris puede moverse arrastrando dos de sus vértices: uno lo gira y el otro lo desplaza. Cuando el triángulo gris está aproximadamente sobre el simétrico del triángulo negro con respecto a la recta, aparece un punto con el letrero "muy bien". La séptima figura tiene un triángulo gris, una recta y un círculo con un punto. El punto sobre el círculo modifica la inclinación de la recta. La diferencia entre las seis primeras figuras es la inclinación de la recta.

\section{Descripción de la actividad}

Se quiere que los alumnos comprendan que para que una figura sea simétrica de otra, cada par de puntos correspondientes deben quedar sobre una recta perpendicular al eje y a igual distancia del mismo, pero en lados opuestos.

En esta actividad los alumnos deben pasar de una problemática de colocar el triángulo "aproximadamente" a construirlo de manera exacta, de manera que se mantenga la simetría.

\section{Primera tarea (en las seis primeras figuras)}

\section{Considerando que la recta representa un espejo, mover el triángulo gris hasta que sea el reflejo del triángulo negro por ese espejo.}

Se espera que los alumnos desplacen el triángulo hasta la posición que ellos anticipan de la imagen del triángulo gris. En ese momento debe aparecer el letrero "¡Muy bien!".

Es probable que con las dos primeras figuras no tengan muchas dificultades, pero en la tercera y cuarta, dada la inclinación del eje, la tarea se torna un poco más compleja, en vista de que deben identificar tanto la perpendicularidad como la equidistancia. Podrían presentarse las siguientes estrategias.

- Construir los puntos medios de dos parejas de puntos, y mover el triángulo negro hasta obtener que esos puntos medios queden sobre la recta (Figura 34). En este caso, el profesor debe mostrar contraejemplos en los que esos puntos medios están sobre la recta, pero los triángulos no son simétricos (pues no se cumple la perpendicularidad). Un posible contraejemplo que podría mostrársele al alumno sería el que se observa en la Figura 34.b, con ello el alumno se percatará que el triángulo gris no es imagen del triángulo negro. 

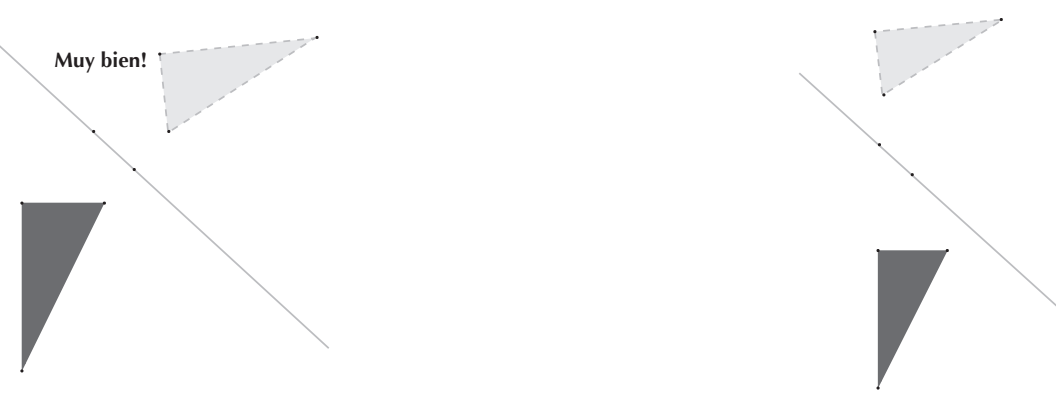

a.

b.

Figura 34. Estrategia 1 de la Actividad 4

- Colocar sobre la recta el vértice del triángulo negro que permite trasladarlo, y hacerlo coincidir con el vértice correspondiente del triángulo gris; luego girar el triángulo gris hasta obtener el letrero (Figura 35). Esta estrategia es correcta, pero el profesor deberá pedirles a estos alumnos que intenten resolver el problema sin mover el triángulo negro, para que utilicen las relaciones entre cada par de puntos simétricos y el eje.

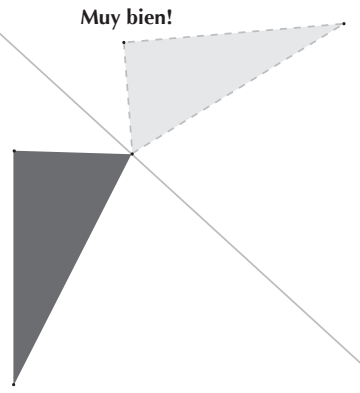

Figura 35. Estrategia 2 de la Actividad 4

- Llevar el triángulo gris y el negro sobre la recta y hacer que las intersecciones de dos pares de lados correspondientes queden sobre ella (Figura 36). 


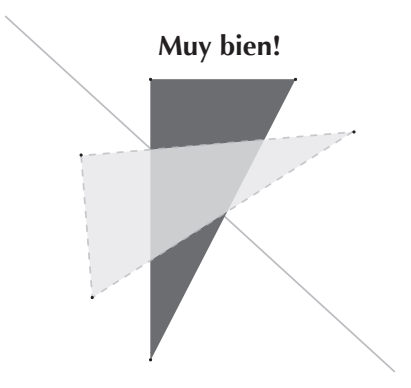

Figura 36. Estrategia 3 de la Actividad 4

Nuevamente esta estrategia es correcta, pero el profesor deberá pedirles a estos alumnos que intenten resolver el problema sin mover el triángulo negro, para que utilicen las relaciones entre cada par de puntos simétricos y el eje.

Al concluir esta tarea, Ilevando a cabo las acciones previstas, los alumnos interpretan que el triángulo gris debe ubicarse de modo que cada vértice de éste y el correspondiente del triángulo negro queden a igual distancia de la recta, pero en lados contrarios y en dirección perpendicular a la recta, refiriéndose ellos a la perpendicularidad con palabras como "derecho", lo cual corresponde al objetivo de la tarea.

\section{Segunda tarea (en la séptima figura)}

Construir un triángulo que sea el reflejo del triángulo dado con respecto a la recta.

Terminada la primera tarea para las seis primeras figuras, el profesor organiza la puesta en común resaltando condiciones para que el triángulo gris sea el reflejo del negro, tales como la equidistancia y la perpendicularidad, sin importar que no sean estos los términos que usen los alumnos para referirse a dicha propiedad.

El profesor terminará la puesta en común mostrando la séptima figura. De manera análoga como se hizo en la segunda tarea de la actividad anterior, se le pide a un alumno que construya un triángulo que sea el reflejo del negro con respecto a la recta, y para verificar construye el simétrico del triángulo negro con respecto a dicha recta. Si el triángulo construido no coincide con esta imagen, permite que el alumno lo ajuste hasta que coincidan exactamente. Luego mueve el punto sobre el círculo, de manera que la recta cambia 
de inclinación, y muestra que el triángulo construido ya no coincide con la imagen del triángulo gris. Entonces borra el triángulo construido por el alumno, y el construido por Cabri, y devuelve el problema a cada estudiante explicando que se trata de hacer una construcción que siempre coincida con la imagen, incluso cuando se mueve el punto sobre el círculo.

Para realizar una construcción que resista el arrastre es necesario utilizar dos propiedades diferentes: la perpendicularidad entre los segmentos que unen puntos correspondientes y la equidistancia entre los puntos correspondientes y el eje de simetría. Proponemos trabajar por separado esas dos propiedades.

Al igual que en la serie 3-7 de la actividad anterior, esta es una actividad de tipo II, diseñada para invalidar las estrategias perceptivas de los alumnos, pero en la que no se espera que encuentren por sí mismos la solución. Solo se espera que formulen lo más claramente posible el problema y lo que necesitan para la solución. En este caso, que enuncien en sus propias palabras la necesidad de producir las dos propiedades de las que hablamos. Podrían decir, por ejemplo, que necesitan que los segmentos entre puntos correspondientes deben "formar una ele" con el eje de simetría, o que deben quedar "derechos" (refiriéndose a la perpendicularidad), y que la distancia de un vértice del triángulo a la recta debe ser la misma que de la recta al punto correspondiente.

\section{Parte 1: Perpendicularidad}

Es posible que algunos alumnos en este momento expresen que necesitan medir distancias o trazar segmentos; y el profesor mostrará cómo hacerlo delante de todos. Entonces los alumnos trazarán "a ojo" segmentos que cumplen las condiciones de la simetría (Figura 37), pero al mover el interruptor esos segmentos dejan de ser perpendiculares al eje.

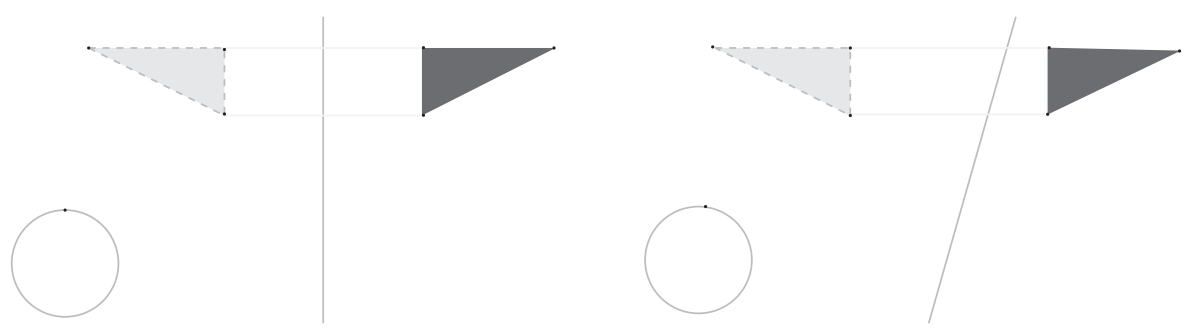

Figura 37. Estrategia 1, segunda tarea 
El profesor debe plantear la pregunta "¿Qué es lo que se pierde al mover el punto sobre el círculo?" Los alumnos podrán expresar con sus propios términos la perpendicularidad ("no está derecho el segmento"; "se torció el segmento", etcétera). Entonces el profesor les pedirá a algunos alumnos que muestren cómo debería estar el segmento con respecto a la recta. Cuando los alumnos expresen en sus palabras que necesitan construir de tal manera que los segmentos sean perpendiculares a la recta, el profesor institucionalizará el término "perpendicular" y mostrará cómo usar la herramienta "recta perpendicular" para obtener la propiedad que ellos esperan.

Es importante dedicar tiempo suficiente para que los alumnos se apropien el uso de la herramienta "recta perpendicular" y experimenten las diferentes posibilidades y las condiciones para poder utilizar dicha herramienta, así como el vocabulario geométrico asociado a esa propiedad. Se recomienda que trabajen en un archivo aparte, y que se den cuenta de que para utilizar la herramienta es necesario que exista en la pantalla un objeto (segmento o recta) de referencia.

También es importante que tomen conciencia de que Cabri espera dos clic para trazar una recta perpendicular: un clic para señalar cuál debe ser perpendicular y un clic para señalar por cual punto debe pasar; el profesor deberá llamar la atención de los alumnos sobre los letreros que aparecen en la pantalla cuando se acerca el cursor a los objetos antes de hacer clic.

Igualmente, es importante que los alumnos se den cuenta que el punto por el que pasará la perpendicular puede estar sobre la recta de referencia o fuera de ella, o que incluso puede crearse "sobre la marcha" (no es necesario que esté creado con anterioridad). Con respecto al vocabulario es necesario evitar expresiones como "la recta es perpendicular al punto X"; el profesor debe señalar que es necesario nombrar dos parámetros, así como Cabri necesita dos clics para construir la perpendicular: un parámetro para señalar a quién es perpendicular y un parámetro para decir por dónde pasa esa perpendicular. Una frase correcta debe decir "recta perpendicular a por el punto ___. Una vez que los alumnos hayan practicado el uso de la herramienta, el profesor debe pedir que la usen en el problema de la serie 4-7.

\section{Parte 2: Equidistancia}

Una vez que han construido la recta perpendicular al eje por uno de los vértices del triángulo, podrán ubicar de manera aproximada un punto sobre esa recta, al lado opuesto del triángulo con respecto al eje, y así construir la imagen del triángulo. Esta relación de equidistancia se perderá al mover el eje de simetría (Figura 38). 
El profesor deberá asegurarse de que los alumnos identifican claramente el problema: “¿Qué es lo que no está funcionando?". Los alumnos deberán responder en sus propias palabras que la distancia de un punto al eje de simetría no es igual a la distancia de su imagen al eje de simetría.

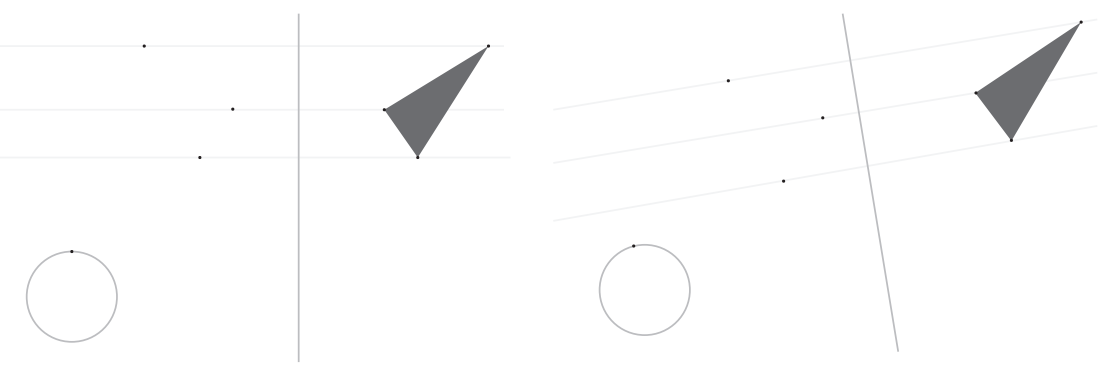

Figura 38. Estrategia 2, segunda tarea

Solo después de que los alumnos hayan identificado claramente la necesidad de lograr la equidistancia con respecto al eje, el profesor muestra cómo usar la herramienta círculo para obtenerla (Figura 39), y explica por qué el círculo asegura la equidistancia (un círculo está formado por todos los puntos que están a igual distancia del centro, por lo tanto los dos puntos que están sobre la recta y el círculo están a igual distancia del centro, es decir, del eje).
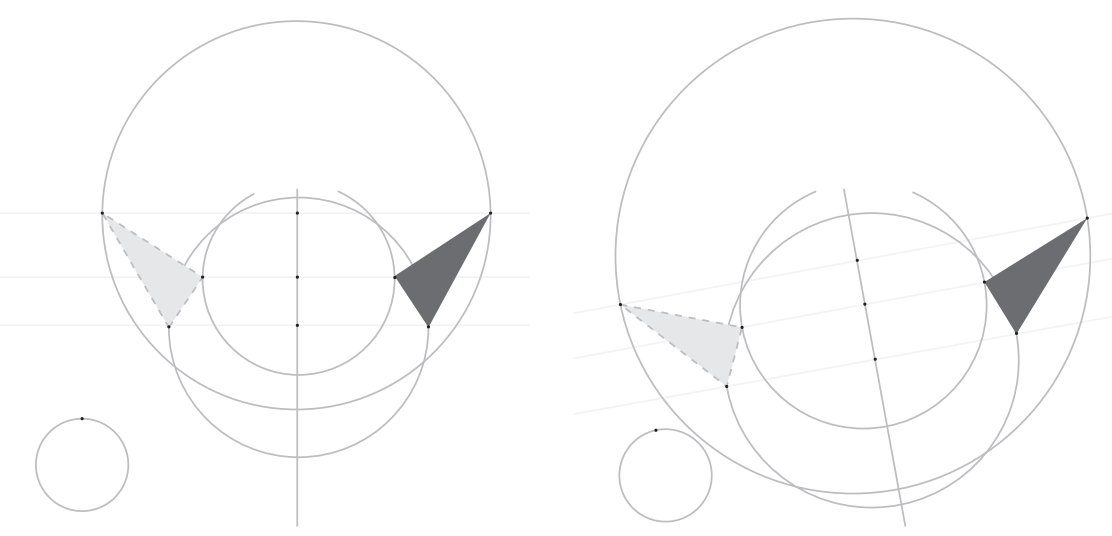

Figura 39. Estrategia 3, segunda tarea 
En conclusión, la única manera de que los alumnos logren resolver la tarea, es que usen tanto la herramienta "recta perpendicular" como la herramienta "círculo" para garantizar la perpendicularidad y la equidistancia respectivamente. De este modo, el producto del aprendizaje por adaptación concuerda con el objetivo planteado, es decir los alumnos comprenderán que un punto y su imagen quedan sobre una recta perpendicular al eje de simetría y a igual distancia de dicho eje.

\section{Institucionalización}

Para la institucionalización se recomienda introducir el vocabulario oficial: "eje de simetría", "figuras simétricas con respecto a un eje", "vértices homólogos o correspondientes", y retomar las distintas actividades para que los alumnos las describan utilizando los nuevos términos. Es importante que el profesor corrija el uso inadecuado de términos, y que los alumnos nombren y escriban correctamente las relaciones de perpendicularidad y equidistancia. Los alumnos deben tener claro que para que haya simetría con respecto a una recta es necesario que los segmentos entre puntos correspondientes sean perpendiculares al eje y que el eje los corte en sus puntos medios.

El profesor debe plantear diferentes situaciones en las que exista o no simetría de dos triángulos con respecto a una recta (tanto dibujos estáticos como dinámicos), y solicitar a los alumnos que justifiquen la simetría o la no simetría haciendo referencia a las propiedades de perpendicularidad, igualdad de distancias o punto medio.

\section{Evaluación}

Aconsejamos realizar una evaluación final por escrito. Se trata de evaluar dos habilidades: dadas dos figuras simétricas construir el eje de simetría y dada una figura y un eje construir la figura simétrica. Además es importante que reconozcan figuras en las que hay simetría y figuras en las que no hay simetría, y que puedan justificar utilizando el saber enseñado (perpendicularidad y equidistancia).

2.2. Ejemplo de enseñanza de construcciones: El Rectángulo

En general, las actividades de construcción están planteadas para que los alumnos pasen de un reconocimiento de una figura geométrica como forma global, es decir como una imagen mental prototípica, al reconocimiento de las partes que lo componen, y de las relaciones entre estas. 
Se busca también que los alumnos aprendan el arrastre de verificación: al resolver un problema de construcción, en la figura ya construida se deben arrastrar todos los elementos que la componen; si la figura pierde sus propiedades, la construcción es incorrecta, si las conserva la construcción es correcta. La secuencia termina con la descripción paso a paso de la construcción.

Pueden plantearse construcciones de diferentes figuras geométricas como triángulos (equilátero, isósceles, rectángulo), cuadriláteros (rectángulo, cuadrado, paralelogramo, rombo). Los ejemplos que presentamos corresponden a la construcción de un rectángulo a partir de un lado y a partir de una diagonal.

Construir un rectángulo a partir de un lado

\section{Saber en juego}

Un rectángulo es un cuadrilátero (4 lados, 4 vértices) que tiene 4 ángulos rectos. Esta definición es mínima; es decir, el rectángulo tiene otras propiedades, pero el hecho de tener 4 ángulos rectos es condición necesaria y suficiente para que sea rectángulo. Por ejemplo, el rectángulo tiene dos pares de lados opuestos paralelos e iguales, por lo tanto es también un paralelogramo. Igualmente, el rectángulo tiene dos diagonales iguales y que se bisecan.

Normalmente, en la geometría de las formas, enseñada en la escuela elemental, se distingue estrictamente entre rectángulo y cuadrado, añadiendo la condición de que dos de sus lados deben ser más largos que los otros dos. En la geometría de las construcciones no se distingue entre rectángulo y cuadrado: todo cuadrado, por tener 4 ángulos rectos es también rectángulo.

En general, en la geometría de la escuela elemental la clasificación de figuras es excluyente: si se identifica una figura como perteneciente a una clase determinada, no puede pertenecer a otra clase. Por el contrario, en la geometría de las propiedades, las clasificaciones no son excluyentes; más bien, se reconoce una estructura de inclusión: una clase de figuras comprende subclases de figuras. Por ejemplo, la clase más amplia de paralelogramos incluye una subclase de rectángulos, y esta a su vez incluye la subclase de los cuadrados; viceversa, todo cuadrado es a la vez rectángulo y paralelogramo. 
Es importante que el profesor sepa que esta forma de clasificar las figuras es nueva para los alumnos, e incluso puede crear conflictos con la clasificación a la que están acostumbrados. No se trata de imponer la nueva clasificación, sino de plantearla como una alternativa, dejando que los alumnos discutan sus pros y sus contras.

Por otra parte, el saber que se espera institucionalizar con esta actividad es el hecho de que dos rectas perpendiculares producen ángulos rectos, o que para producir un ángulo recto es necesario garantizar que dos rectas sean perpendiculares.

\section{Objetivos}

Esta actividad tiene varias finalidades: una de ellas es naturalmente la construcción del concepto de rectángulo como cuadrilátero de cuatro ángulos rectos, pero no es la principal. Como queremos que los alumnos pasen de una geometría de las formas a una geometría de las propiedades (ver marco teórico), en esta actividad aprenderán a distinguir entre un dibujo y una figura. En la geometría de las propiedades, un dibujo es una imagen estática que representa una figura, pero que al arrastrar los objetos que la componen (puntos, rectas, segmentos, círculos) pierde su forma. En cambio, una figura conserva sus propiedades (y por lo tanto su forma) al arrastrar los objetos que la componen. Un dibujo se produce perceptivamente, y trata de reproducir una forma prototípica (una imagen mental), mientras que una figura es resultado de un proceso de construcción, en el cual se explicitan las propiedades fundamentales que debe cumplir, y que por lo tanto se mantendrán a pesar del arrastre de los elementos que la componen.

Queremos que los alumnos comprendan la diferencia entre dibujar un rectángulo (reproducir una forma prototípica) y construir un rectángulo (utilizando sus propiedades). La herramienta didáctica para distinguir entre dibujo y figura es el arrastre de validación, que fue introducido en las actividades de transformaciones.

Hay que advertir al profesor que aunque aparentemente esta actividad es muy simple, para los estudiantes no lo es, pues sus estrategias (perceptivas) de dibujo son infalibles, ya que dan resultados en la mayoría de las situaciones que se les presentan en la vida y en la escuela. Por lo tanto, es normal que los alumnos no abandonen fácilmente esas estrategias perceptivas y que constantemente vuelvan a utilizarlas, a pesar de que el medio (Cabri) las invalide. El profesor debe insistir en que los alumnos hagan la validación por arrastre, hasta que se convenzan de la inutilidad de las estrategias perceptivas (por lo menos en el contexto de los dibujos dinámicos de Cabri). 
Otra de las finalidades de esta actividad es la identificación perceptiva de la propiedad de perpendicularidad o de ángulo recto, y el aprendizaje de su construcción. Específicamente, se espera que los alumnos reconozcan si dos segmentos forman un ángulo recto (es decir, si son perpendiculares) o no, y que utilicen ese conocimiento como criterio para decidir si un dibujo representa o no un rectángulo. Además, se espera que los alumnos lleguen a tomar conciencia de que necesitan una estrategia para lograr que esa propiedad de ángulo recto o perpendicularidad no se pierda al arrastrar los elementos que la componen. Esa estrategia ganadora consiste en utilizar la herramienta "Recta perpendicular", que garantiza que dos objetos sean perpendiculares, incluso al arrastrar los elementos que los definen.

Esta actividad es de tipo II. Es decir, no esperamos que los alumnos descubran por sí mismos la estrategia ganadora; únicamente esperamos que invaliden sus estrategias perceptivas, e identifiquen claramente la necesidad de una estrategia para lograr que "los ángulos no dejen de ser rectos al arrastrar". En el momento en que los alumnos han identificado explícitamente esa necesidad, el profesor podrá proponer la estrategia ganadora, y mostrar el uso de la herramienta "recta perpendicular".

\section{Descripción del medio}

Para esta actividad, se trabaja con la siguiente figura (Figura 40), que puede identificarse como la representación de una casa.

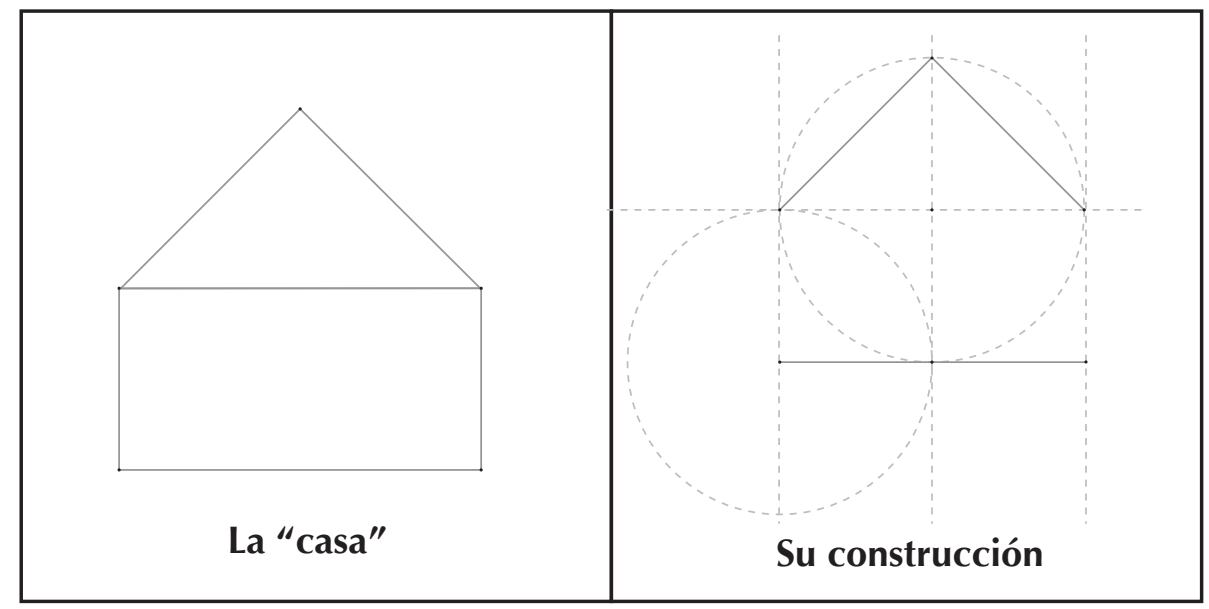

Figura 40. Representación de una casa 
En esta figura solo pueden arrastrarse los dos puntos inferiores, todos los demás puntos dependen de ellos. Al arrastrar uno de esos puntos la figura completa conserva su forma (de "casa") y gira alrededor del otro punto. Puede cambiar de tamaño.

La figura ha sido construida con una macro, con el fin de que si los alumnos utilizan la herramienta "ocultar/mostrar", no encuentren ningún objeto fuera de los que ya están visibles en la pantalla.

\section{Descripción de la actividad}

Se quiere que los estudiantes invaliden las estrategias perceptivas de construcción, y comprendan la diferencia entre dibujo y figura. Que utilicen su conocimiento perceptivo de ángulo recto para decidir si un dibujo representa o no un rectángulo, y que formulen la necesidad de una estrategia para lograr que "un ángulo no deje de ser recto al arrastrar".

\section{Primera fase: reproducción perceptiva de un dibujo}

El profesor les pide que abran el archivo preparado, y que describan lo que ven. Se espera que la mayoría de los estudiantes digan que eso es una casa. Entonces el profesor les propone la tarea: deben reproducir ese dibujo (en el mismo archivo, al lado). Se espera que los alumnos exploren las diferentes herramientas disponibles, y utilicen "segmento", "polígono" o "triángulo" para hacer su dibujo.

Cuando todos los alumnos hayan terminado sus dibujos, el profesor les pide que arrastren los diferentes puntos de la figura que él propuso y observen lo que sucede. Luego que arrastren los diferentes puntos de la figura que ellos construyeron y observen lo que sucede. Evidentemente, los alumnos identifican rápidamente la diferencia entre las dos: la figura propuesta por el profesor no pierde su forma de "casa", mientras que la figura construida por ellos sí la pierde. El profesor entonces plantea el problema: deben construir una figura que no pierda su forma al arrastrar los puntos que la componen.

- Estrategia 1: utilizar la herramienta segmento, y construir de manera perceptiva la casa, ajustando los puntos para que la figura tenga la misma forma que el modelo.

- Estrategia 2: utilizar la herramienta polígono para producir la parte de abajo de la "casa", y la herramienta triángulo para la parte de arriba.

- Estrategia 3: utilizar la opción copiar/pegar para producir la imagen de la casa modelo. 
Todas estas estrategias son perdedoras, pues al arrastrar los objetos que componen los dibujos, estos pierden la forma de casa.

- Estrategia 4: utilizar la herramienta traslación (o simetría axial o simetría central) para producir la imagen de la casa modelo por esa transformación.

Sí es posible producir así una figura que tenga la misma forma, pero no pueden arrastrarse los puntos que la forman.

\section{Segunda fase: identificación de figuras geométricas y reducción del problema}

Después de dejarlos intentar diferentes estrategias, el profesor interviene para señalar: "La clave para resolver el problema está en examinarlo desde el punto de vista de la geometría". Propone entonces no describir la figura como una "casa", sino describirla geométricamente, y pide a los alumnos hacer una descripción geométrica.

Es posible que los alumnos digan que la figura está compuesta por un rectángulo y un triángulo. Entonces el profesor propone reducir el problema a construir un rectángulo.

Nuevamente, los alumnos utilizan estrategias perceptivas para construir el rectángulo: unir segmentos, utilizar polígono (es posible que utilicen polígono regular y lo utilicen para construir un rectángulo).

También es posible que los alumnos comprendan el problema de una manera diferente, como encontrar la manera de que no se "desbarate" la figura, es decir que no se puedan mover los puntos. Por ejemplo, en la siguiente figura (Figura 41) la construcción es perceptiva, pero los vértices del rectángulo no se pueden arrastrar, y por lo tanto no pierde su forma.

Figura 41. Construcción perceptiva 
Al ocultar los segmentos que sirvieron de base para la construcción, solo queda visible el rectángulo (Figura 42):

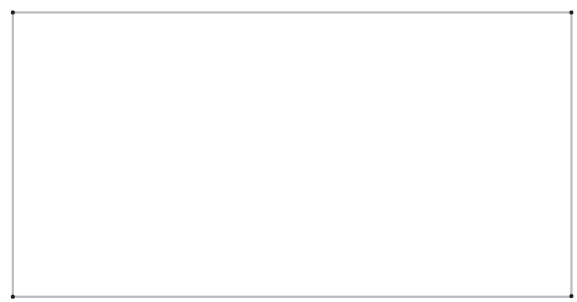

Figura 42. Rectángulo construido perceptivamente

¿Cómo puede el profesor identificar que esto no es una figura sino un dibujo, y cómo puede organizar la invalidación por parte del medio? El profesor debe tener en cuenta que al menos dos puntos deben poder arrastrarse, y la figura debería cambiar de tamaño pero no de forma. Si esto no se cumple, es porque los puntos visibles dependen de objetos que están ocultos. Entonces debe aclarar que el arrastre de verificación debe aplicarse a todos los objetos que componen la figura; tanto los visibles como los ocultos.

Debe pedir a los alumnos que muestren todos los objetos que están ocul$\operatorname{tos}^{3}$ y que les apliquen el arrastre. En este caso, la figura queda invalidada al arrastrar alguno de los puntos de base (Figura 43):

Figura 43. Invalidación por el arrastre

3 Seleccionar la herramienta Ocultar/Mostrar, llevar el cursor a un punto vacío de la pantalla, oprimir la tecla Shift y hacer clic. 


\section{Tercera fase: identificación de propiedades y reducción del problema}

Una vez invalidadas todas esas estrategias, el profesor propone nuevamente examinar el problema desde el punto de vista de la geometría: ¿Qué es un rectángulo en geometría?

Se espera que los alumnos logren precisar que es una figura de cuatro lados, con cuatro ángulos rectos. Entonces el profesor propone una nueva reducción del problema: construir un ángulo recto. Los alumnos utilizarán de nuevo estrategias perceptivas (utilizando las herramientas segmento, recta o semirrecta) para hacer la construcción, pero no resistirán el arrastre.

\section{Cuarta fase: identificación del problema, propuesta de solución}

Una vez que los alumnos han invalidado diferentes estrategias perceptivas por medio del arrastre, el profesor debe verificar que han identificado la dificultad: cómo hacer para que el ángulo sea recto incluso al arrastrar los objetos que lo componen. Entonces puede proponerles la estrategia solución: utilizar la herramienta "recta perpendicular".

El profesor debe mostrarles la herramienta y enseñarles su uso. En un archivo aparte, debe mostrar a los alumnos que para utilizar la herramienta "recta perpendicular" es necesario que en la pantalla ya se haya trazado un objeto (segmento, recta, semirrecta) a quien ser perpendicular, y que es necesario hacer dos veces clic: una para señalar el objeto a quien la recta debe ser perpendicular, y otra para especificar un punto por el cual debe pasar esa perpendicular. En efecto, existen infinitas rectas perpendiculares a un objeto dado, por lo que es necesario definir cuál de todas ellas se quiere trazar. También es importante que el profesor muestre que el punto por el cual va a pasar la recta perpendicular puede estar sobre el objeto al que es perpendicular la recta, o puede estar por fuera de él, y que no es necesario crearlo de antemano: al hacer clic en cualquier parte de la pantalla Cabri construye dicho punto y por él traza la perpendicular.

Cuando los alumnos ya saben construir un ángulo recto que resista el arrastre, el profesor les propone de nuevo el problema de construir un rectángulo que resista el arrastre.

Una vez que los alumnos hayan construido tres rectas perpendiculares los cuatro ángulos construidos son rectos, pero seguramente querrán borrar parte de las rectas construidas para quedarse únicamente con el polígono. El profesor debe mostrar que si se borra una recta, desaparece completamente 
el ángulo que ella formaba. Por eso es necesario no borrar, sino ocultar las rectas, de manera que no se ven en la pantalla pero los objetos que dependen de ellas no desaparecen.

\section{Tipos de estrategias}

Es posible que algunos alumnos sigan utilizando estrategias puramente perceptivas para la construcción del rectángulo, estrategias que quedarán invalidadas por el arrastre.

Algunos alumnos utilizarán estrategias de construcción con la herramienta "recta perpendicular" para producir los cuatro ángulos rectos. Estas estrategias quedarán validadas por el arrastre.

Algunos alumnos utilizarán estrategias mixtas: es decir, para algunos ángulos utilizarán la herramienta "recta perpendicular" y para otros utilizarán la percepción. En este caso, el arrastre de algunos puntos no invalidará la construcción, pero hay que recordar que la prueba del arrastre debe aplicarse a todos los objetos, visibles y ocultos.

Recordamos al profesor que es posible que los alumnos insistan en utilizar las estrategias perceptivas a pesar de quedar invalidadas por el arrastre. Esto es normal, pues en la mayoría de las situaciones, estas estrategias perceptivas son ganadoras. No hay que tratar de forzar a esos alumnos a abandonar esas estrategias, sino insistir en utilizar el arrastre para validar, de manera que las invaliden.

Existen muchas posibilidades de construcción de un rectángulo utilizando la herramienta recta perpendicular. Cada una de ellas producirá rectángulos que se mueven de diferentes maneras, aunque todos conservan los cuatro ángulos rectos durante el arrastre. Por ejemplo, si se construye el rectángulo partiendo de una recta sobre la que se colocan dos puntos que serán vértices del rectángulo, al arrastrar esos puntos no podrán salirse de la recta de base; el rectángulo podrá agrandarse o achicarse, pero no podrá girar al arrastrar sus vértices; solo girará al arrastrar la recta de base. Por el contrario, si se hace la construcción a partir de un segmento, los extremos de ese segmento podrán arrastrarse libremente, haciendo que el rectángulo gire y cambie de tamaño.

\section{Quinta fase: describir una construcción}

Para terminar esta actividad es importante que los alumnos aprendan a describir paso a paso una construcción, pues en adelante tendrán que repetir construcciones o analizarlas para decidir si son válidas o no. 
Proponemos al profesor que utilice la herramienta "mostrar descripción" para hacer la descripción. Esa herramienta se encuentra en el menú "opciones", y abre una ventana lateral con la descripción de la construcción.

Es importante darle nombre a todos los objetos construidos (puntos, rectas, segmentos, etcétera) para poder identificarlos en la descripción. Una vez nombrados todos los objetos de la construcción, en la descripción que muestra Cabri no debería haber espacios vacíos. Al hacer clic derecho sobre esa descripción es posible copiarla en el portapapeles para pegarla en un documento de texto o en una tabla de datos. Una vez allí es necesario modificar la sintaxis para que sea más comprensible.

Ejemplo de una descripción de Cabri:

\begin{tabular}{|ll|l|}
\hline \multicolumn{2}{|c|}{ Descripción de Cabri } & \multicolumn{1}{c|}{ Descripción corregida } \\
\hline A & Punto & Segmento AB \\
B & Punto & r1 perpendicular a AB por A \\
AB & Segmento: A, B & r2 perpendicular a AB por B \\
r1 & Recta (Recta perpendicular): A, AB & C punto sobre r2 \\
r2 & Recta (Recta perpendicular): B, AB & r3 perpendicular a r2 por C \\
C & Punto (Punto sobre un objeto): r2 & D punto de intersección de r1 \\
r3 & Recta (Recta perpendicular): C, r2 & y r3 \\
D & Punto (Punto(s) de intersección): r1, r3 & Polígono ABCD \\
& Polígono: A, B, C, D & \\
\hline
\end{tabular}

\section{Institucionalización}

Es fundamental que se institucionalicen los siguientes saberes:

1. Un rectángulo es un cuadrilátero con cuatro ángulos rectos.

2. Si dos rectas son perpendiculares, los ángulos que forman son rectos.

3. Si se quiere construir un ángulo recto que resista el arrastre, es necesario utilizar la herramienta "recta perpendicular".

4. La forma correcta de nombrar rectas perpendiculares es nombrando tres objetos, como por ejemplo: la recta $\mathrm{r}$ es perpendicular a la recta s por el punto $P$. 
Construcción de un rectángulo a partir de la diagonal (construir un ángulo recto sin utilizar recta perpendicular]

\section{Saber en juego}

La diagonal de un rectángulo es la hipotenusa de un triángulo rectángulo. Todo triángulo inscrito en una semicircunferencia es rectángulo. Si un ángulo tiene su vértice sobre un círculo y sus extremos forman un diámetro de ese círculo, entonces es un ángulo recto.

Es posible construir un ángulo recto a partir de una circunferencia, un diámetro de la circunferencia y un punto sobre la circunferencia (sin utilizar la herramienta "recta perpendicular".

\section{Objetivos}

Se trata de que los alumnos descubran que es posible construir un ángulo recto sin utilizar la herramienta "recta perpendicular", y de esa manera construir un rectángulo a partir de su diagonal.

\section{Descripción del medio}

En esta actividad se utiliza un rectángulo construido como una macro para que los alumnos no puedan descubrir cómo fue construido utilizando la herramienta "ocultar/mostrar". La construcción es la siguiente:

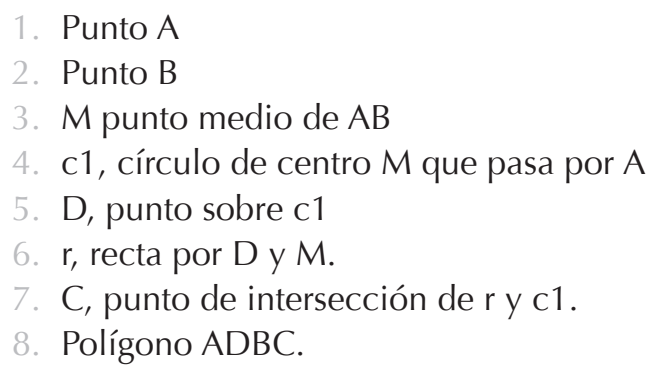

Se espera que los alumnos experimenten el arrastre de los cuatro vértices del rectángulo, primero para invalidar la estrategia de construir a partir de un lado, segundo para descubrir un procedimiento de construcción.

Es necesario que los alumnos conozcan la distinción entre puntos libres, puntos sobre objeto y puntos de intersección, para lo cual es necesaria una actividad previa de clasificación de puntos de una figura dinámica. 
Actividad previa: clasificación de puntos de una figura dinámica

Se construye la siguiente figura, en la que hay dos rectas secantes, un círculo que corta una de las rectas, seis puntos y seis círculos pequeños (Figura 44).

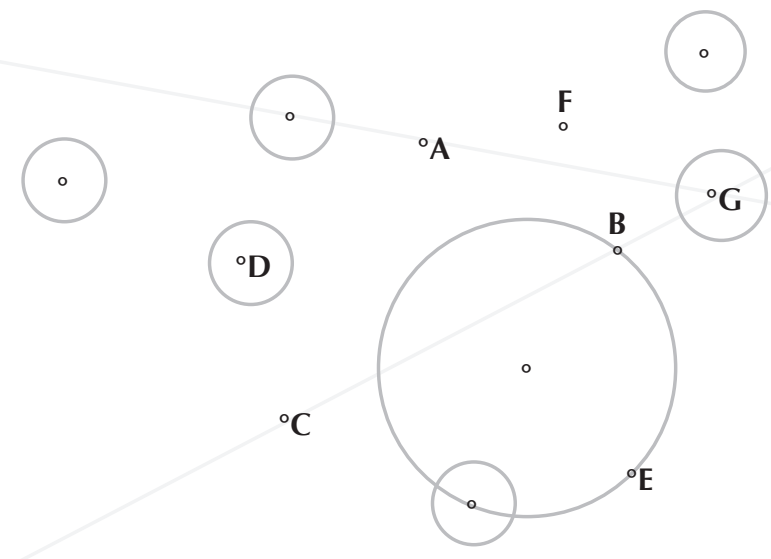

Figura 44. Clasificación de puntos

Se ocultan las dos rectas, el círculo grande y los centros de los círculos pequeños de manera que queda visible la siguiente figura (Figura 45):
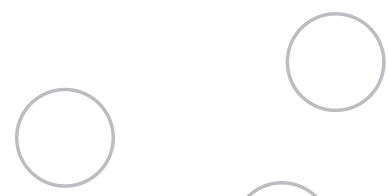

${ }^{\circ} \mathrm{D}$

${ }^{\circ} \mathrm{A}$

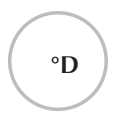

${ }^{\circ} \mathrm{C}$

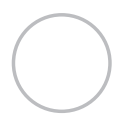

Figura 45. Rectas y puntos ocultos 
Los puntos $A, C, D, E$, F podrán moverse, los puntos B y $G$ no se dejan arrastrar, así como los círculos pequeños. Se solicita a los alumnos que metan todos los puntos sucesivamente en cada uno de los círculos.

Al intentar arrastrar cada uno de los puntos, los alumnos podrán constatar que algunos de ellos no se pueden desplazar, otros se desplazan pero no pueden llevarse a cualquier parte de la pantalla, mientras que otros sí se pueden llevar a cualquier parte de la pantalla. Si intentan desplazar los círculos constatarán que no es posible.

El profesor les solicita entonces que clasifiquen los puntos en tres clases:

- Los que pueden meterse en todos los círculos

- Los que solo pueden meterse en algunos círculos

- Los que no pueden meterse en ningún círculo

- Finalmente organiza una puesta en común para que los alumnos muestren y justifiquen sus clasificaciones, y termina institucionalizando de la siguiente manera:

- Llamamos "punto libre" a un punto que se pueda arrastrar a cualquier parte de la pantalla.

- Llamamos "punto sobre objeto" a un punto que se puede arrastrar pero no puede llevarse a cualquier parte de la pantalla.

- Llamamos "punto de intersección" a un punto que no se puede arrastrar.

El profesor hará notar que en el menú "Punto", Cabri tiene estos tres tipos de puntos, y solicitará que deduzcan sobre qué objetos se mueven los "puntos sobre objeto" de la figura que están trabajando (rectas y círculo). Para verificar esas conjeturas les mostrará el uso de la herramienta "traza", aplicándola a los puntos sobre objeto.

\section{Primera fase: planteamiento del problema}

El profesor le pide a los alumnos que abran la figura donde está el rectángulo construido a partir de la diagonal, en posición prototípica, y les pide que describan esa figura. Ellos dirán que es un rectángulo. Luego les pide que construyan una figura igual.

Los alumnos construirán un rectángulo a partir de un lado, como lo hicieron en la actividad anterior. En ese momento el profesor les pide que arrastren los diferentes vértices de la figura dada y de la figura que ellos construyeron, y concluyan si se mueven de la misma manera. Ellos concluirán que no se mueven de la misma manera. Finalmente, el profesor les pide que hagan una construcción en la que los puntos "se muevan igual que en el modelo". 
Si los alumnos no lo hacen de manera espontánea, el profesor les sugiere que clasifiquen los puntos de la figura modelo según los criterios acordados en la actividad previa de clasificación de puntos dinámicos.

Los alumnos concluirán entonces que dos vértices opuestos son puntos libres, un tercer vértice es punto sobre objeto y el cuarto es punto de intersección. Luego buscarán cuál es el objeto sobre el que se mueve el "punto sobre objeto", para lo cual podrán utilizar la herramienta "traza". Una vez que han identificado que ese objeto es un círculo, podrán resolver el problema.

El profesor institucionaliza el siguiente saber: "dados dos puntos A y B, si se construye un círculo de diámetro $\mathrm{AB}$ y se toma un punto $\mathrm{C}$ de ese círculo, el ángulo ACB es recto".

\subsection{Ejemplo de actividades con lugares geométricos: la mediatriz}

Los lugares geométricos se utilizan con frecuencia en la solución de problemas de geometría y están en la base de muchos razonamientos y demostraciones. Sin embargo, en el currículo "tradicional" solo se trabajan en grado décimo, al considerar las cónicas como lugares geométricos. Por nuestra parte, consideramos que pueden introducirse de manera temprana en la enseñanza, como estrategia de solución de problemas, teniendo en cuenta que el software de geometría incluye las herramientas "traza" y "lugar geométrico".

En esta propuesta de actividad se propone el reconocimiento y la institucionalización de la mediatriz como lugar geométrico, utilizando la "técnica del hilvanado" en la cual se parte de un dibujo aproximado para deducir las propiedades del lugar buscado. Esta técnica de hilvanado puede utilizarse para trabajar otros lugares geométricos utilizados frecuentemente en geometría elemental, como el círculo (lugar de todos los puntos equidistantes del centro, la bisectriz (lugar de todos los puntos equidistantes de dos semirrectas de extremo común) y el arco capaz (lugar de todos los puntos que forman un ángulo de medida fija con respecto a dos puntos dados). 


\section{Primera fase: planteamiento del problema}

El profesor escribe el siguiente enunciado en el tablero:

"Dados dos puntos A y B, construir 20 puntos $\mathrm{P}$ tales que AP=PB". Y sugiere utilizar la técnica del hilvanado que describe de la siguiente manera:

1. Construir los puntos A y B.

2. Construir un punto libre $P$.

3. Medir AP y PB.

4. Arrastrar P hasta que AP sea más o menos igual a PB.

5. Construir un segundo punto $P$.

6. Repetir desde el paso 3.

Los alumnos podrán comenzar a utilizar directamente la técnica del hilvanado, o podrán construir algunos puntos que ya saben que son equidistantes de $A$ y $B$ : el punto medio de $A B$, y los vértices del cuadrado de diagonal $A B$. Es posible que algunos alumnos aseguren que no es posible construir más puntos que cumplan la condición. El profesor insistirá en que apliquen la "técnica del hilvanado". Una vez que han encontrado más de cinco puntos que cumplan aproximadamente la condición, comenzarán a buscar otras posiciones hasta completar los 20 puntos pedidos.

Es importante la experimentación con el arrastre de los puntos para lograr que las dos distancias sean iguales, pues durante esa experimentación los alumnos constatan que hay regiones del plano donde una distancia es mayor que la otra, lo cual refuerza la convicción de que los puntos solución se encuentran sobre una línea recta (frontera de las dos regiones del plano).

Se espera que los alumnos comiencen de manera espontánea a afirmar que todos los puntos están sobre una misma recta, y entonces el profesor les pedirá que construyan esa recta, para lo cual es necesario que identifiquen que debe ser perpendicular al segmento $A B$ y pasar por su punto medio.

Finalmente, el profesor les pide una construcción que resista el arrastre: es decir, dados los puntos A y B, construir 20 puntos que estén a igual distancia de $A$ y de $B$, incluso cuando se arrastren los puntos $A$ y $B$.

Se espera que en la puesta en común la mayoría de los alumnos hayan logrado esa construcción que resiste el arrastre, lo cual posibilita al profesor realizar la institucionalización en los siguientes términos: "Se llama mediatriz de dos puntos a la recta perpendicular al segmento formado por los dos puntos y que pasa por su punto medio". "Todo punto sobre la mediatriz de 
un segmento equidista de los extremos del segmento". "Si un punto está a igual distancia de dos puntos dados, entonces está sobre la mediatriz de esos dos puntos".

\section{Segunda fase: aplicación y razonamiento}

El interés de los lugares geométricos no está en su identificación o clasificación, sino en su uso como herramienta de solución de problemas. Por eso se continúa esta actividad planteando un problema en el que los alumnos tienen oportunidad de utilizar el conocimiento recién construido e institucionalizado.

Se plantea el siguiente problema:

"Dados tres puntos A, B y C, construir 20 puntos que estén a igual distancia de $A$, de B y de C".

Se espera que los alumnos reutilicen la técnica del hilvanado para buscar puntos que cumplan la condición, y se den cuenta de que no es posible encontrar muchos puntos. Entonces el profesor les pide apagar los computadores para analizar el problema utilizando los conocimientos teóricos y poder predecir la posición de los puntos solución. Puede proponerles hacer un dibujo en el papel con los tres puntos, y realizar el siguiente razonamiento:

- Como los puntos buscados deben estar a igual distancia de A, B y C, entonces deben estar a igual distancia de A y B. Si olvidamos momentáneamente $\mathrm{C}$, ¿qué podemos decir de los puntos que están a igual distancia de $\mathrm{A}$ y $\mathrm{B}$ ?

- Se espera que los alumnos recuerden el trabajo anterior y digan que están sobre la mediatriz de $\mathrm{AB}$ y dibujen dicha mediatriz.

- Ahora, si olvidamos momentáneamente A, ¿Qué podemos decir de los puntos que están a igual distancia de B y C?

- Se espera que los alumnos digan que están sobre la mediatriz de BC y la dibujen.

- Como los puntos buscados tienen que estar a igual distancia de A y B, deben estar sobre la mediatriz de $\mathrm{AB}$, y como tienen que estar a igual distancia de $\mathrm{B}$ y $\mathrm{C}$, deben estar sobre la mediatriz de BC.

Se espera que los alumnos concluyan que necesariamente los puntos buscados deben estar en la intersección de las dos mediatrices. Este razonamiento es producido en un diálogo entre el profesor y los alumnos, diálogo que los alumnos pueden seguir y comprender, pero que no esperamos que sean capaces de producir solos. El razonamiento deductivo que caracteriza 
ese diálogo no surge espontáneamente en los alumnos, pero estos pueden apropiárselo a partir de las propuestas del profesor y los conocimientos que ellos mismos han construido. Así que esperamos que puedan reproducir esa forma de razonamiento al enfrentarse a otros problemas.

Es importante el hecho de apagar el computador, para liberar la atención de lo visual, aparente en la pantalla, y prestar atención a lo teórico, es decir a los conocimientos que anticipan lo visual. Pero después de realizar el razonamiento debe ponerse a prueba en una construcción dinámica, y ser sometida a la prueba del arrastre.

\subsection{Ejemplo de actividades de justificación}

Después de trabajar los problemas de construcción (producción de una figura que resiste el arrastre, es decir una figura en la que se garantizan determinadas propiedades por medio de un procedimiento de construcción), y se aprovechan las soluciones de estos problemas para institucionalizar afirmaciones generales que corresponden a "hechos geométricos" encontrados experimentalmente, por ejemplo: dos rectas perpendiculares garantizan que los ángulos formados por ellas son rectos, todo punto sobre una circunferencia forma ángulos rectos con extremos de un diámetro de esa circunferencia, todo punto de la mediatriz de un segmento equidista de los extremos de ese segmento), puede pasarse al terreno de la justificación. En esta etapa sugerimos tomar las descripciones de las construcciones y trabajar con esos textos en lugar de trabajar directamente con las figuras dinámicas, planteando el problema de "justificar que una propiedad se cumple".

Vamos a presentar un ejemplo, retomando la construcción del rectángulo a partir de un lado, problema ya expuesto anteriormente. Recordemos primero una posible construcción de esta solución:

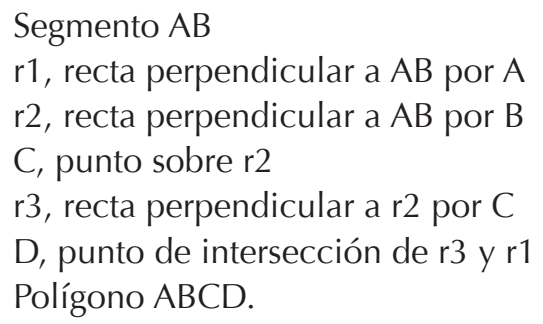


Se plantea a los alumnos el problema de justificar que ABCD es un rectángulo, sin recurrir al arrastre. Para justificar que $A B C D$ es un rectángulo, deben justificar que los ángulos $\mathrm{ABC}, \mathrm{BCD}, \mathrm{CDA}$ y $\mathrm{DAB}$ son rectos. Y los alumnos cuentan con un hecho geométrico ya institucionalizado: "Si dos rectas son perpendiculares, entonces forman ángulos rectos". O también pueden decir que si se utiliza la herramienta "recta perpendicular", el ángulo resultante debe ser recto.

Como en la construcción se utilizó tres veces la herramienta recta perpendicular, es posible justificar que tres de sus ángulos son rectos:

- En el paso 2 se construyó una recta r1 perpendicular a AB por A, y luego el punto $D$ está sobre esa recta (paso 6), por lo tanto la recta DA es perpendicular a la recta $A B$ y el ángulo $D A B$ es recto.

- En el paso 3 se construyó r2 perpendicular a AB por B, y luego el punto $C$ está sobre esa recta (paso 4), por lo tanto la recta $A B$ es perpendicular a la recta $\mathrm{BC}$ y el ángulo $\mathrm{ABC}$ es recto.

- En el paso 5 se construyó r3 perpendicular a r2 (BC) por C, y luego el punto $\mathrm{D}$ sobre esa recta (paso 6), por lo tanto la recta $\mathrm{BC}$ es perpendicular a la recta $\mathrm{CD}$ y el ángulo BCD es recto.

Pero no se construyó ninguna recta perpendicular por el punto D, con lo cual no se puede justificar que el ángulo CDA es recto utilizando el hecho geométrico institucionalizado.

El profesor debe asegurarse que los alumnos comprenden que en realidad ellos no "le solicitaron al software que ese ángulo fuera recto", a diferencia de los otros ángulos. Es decir, esa propiedad no es resultado directo del uso de una herramienta de construcción, y por lo tanto es necesario encontrar otra manera de justificarla.

Una vez planteada esa necesidad, el profesor puede plantear el siguiente problema intermedio para introducir una nueva forma de justificar que el ángulo CDA es recto:

"Construya tres rectas $f, g$ y $h$, de manera que g sea perpendicular a $f, h$ sea perpendicular a $g$, y $f$ sea perpendicular a $h$ ". Se espera que los alumnos hagan espontáneamente la siguiente construcción (o una equivalente):

Una recta $f$.

2. g, perpendicular a f por un punto cualquiera.

h, perpendicular a g por un punto cualquiera. 
Deberían constatar que las rectas $f$ y $h$ no resultan perpendiculares, sino paralelas. El profesor nuevamente debe hacer tomar conciencia a los alumnos que esa propiedad de paralelismo no es consecuencia del uso de la herramienta "recta paralela", sino más bien de la doble utilización de la herramienta "recta perpendicular", de manera que puede afirmarse lo siguiente: "si dos rectas son perpendiculares a una misma recta, entonces son paralelas entre sí".

Luego propone a sus alumnos que hagan la siguiente construcción:

1. Una recta $m$,

2. $n$, paralela a $m$ por un punto cualquiera

3. o, perpendicular a $\mathrm{n}$ por un punto cualquiera

Y les pregunta: “¿Qué relación hay entre m y o? Se espera que los alumnos respondan que son perpendiculares. ¿Ustedes utilizaron la herramienta "recta perpendicular" para garantizar que esas rectas fueron perpendiculares? Nuevamente, se trata de hacer tomar conciencia de que esa perpendicularidad no es resultado directo de la utilización de la herramienta, sino más bien de la combinación de las otras dos propiedades, y puede institucionalizarse el hecho geométrico: "Si dos rectas son paralelas, toda recta perpendicular a una de ellas será también perpendicular a la otra".

Una vez institucionalizados estos dos hechos geométricos, el profesor les propone a los alumnos retomar el problema de justificar la construcción del rectángulo, y del hecho que el ángulo CDA es recto.

Según la construcción, la recta $A D$ ( $r 1$ ) es perpendicular a la recta $A B$ y la recta $\mathrm{BC}(\mathrm{r} 2)$ es perpendicular a la recta $\mathrm{AB}$. Las dos rectas $\mathrm{AD}$ y $\mathrm{BC}$ son perpendiculares a una misma recta $A B$, por tanto son paralelas, según la conclusión del experimento.

Por otra parte, la recta $C D(r 3)$ es perpendicular a la recta $B C(r 2)$. Como $A D$ es paralela a $B C$ y $B C$ es perpendicular a $C D$, entonces $C D$ es perpendicular a AD, según la conclusión del experimento. Así que el ángulo ADC es recto, pues las rectas $A D$ y $D C$ son perpendiculares. De esta manera queda justificado que los cuatro ángulos del cuadrilátero $A B C D$ son rectos, y que por lo tanto es un rectángulo. 
Brousseau, G. y Balacheff, N. (1998). Théorie des situations didactiques (Didactique des mathématiques 1970-1990). Grenoble: La pensée sauvage.

Fiallo, J. (2011). Estudio del proceso de demostración en el aprendizaje de las razones trigonométricas en un ambiente de Geometría Dinámica (Tesis doctoral). Universidad de Valencia.

Margolinas, C. (1993). De l'importance du vrai et du faux dans la clase de mathématiques. Grenoble: La pensée sauvage. 
Sobre los autores

\section{Martín Eduardo Acosta Gempeler}

Profesor investigador de la Universidad Distrital Francisco José de Caldas. Doctor en Didáctica de las Matemáticas de la Universidad Joseph Fourier de Grenoble, Francia (2008), Magister en Didáctica de las Matemáticas de la Universidad Joseph Fourier de Grenoble, Francia (2003), Licenciado en Ciencias de la Educación con especialización en Matemáticas de la Pontificia Universidad Javeriana de Bogotá (1988). Su campo de investigación se centra en la Didáctica de la Geometría, la Formación de Profesores y el uso de las Tecnologías Digitales en la Enseñanza y el Aprendizaje de las Matemáticas. Es profesor en la Licenciatura en Educación Básica con Énfasis en Matemáticas, en la Maestría en Educación y en el Doctorado en Educación de la Universidad Distrital. Es miembro del Grupo de Investigación en Educación Matemática EDUMAT, grupo interinsitucional UIS-UD.

\section{Jorge Enrique Fiallo Leal}

Profesor investigador de la Universidad Industrial de Santander. Doctor en Didáctica de las Matemáticas de la Universidad de Valencia, España (2011), Magister en Didáctica de las Matemáticas de la Universidad de Valencia, España (2006), Magister en Enseñanza de la Matemática de la Universidad Industrial de Santander (1996), Licenciado en Matemáticas de la Universidad Industrial de Santander (1990). Su campo de investigación se centra en la Didáctica de la Geometría y del Cálculo, la Demostración en la Enseñanza y el Aprendizaje de las Matemáticas, y el uso de las Tecnologías Digitales en la Enseñanza y el Aprendizaje de las Matemáticas. Su labor docente se centra en las materias de Didáctica de la Geometría, Didáctica del Cálculo, Geometría Euclidiana, Cálculo Diferencial e Integral y Álgebra Lineal. Es director del Grupo de Investigación en Educación Matemática EDUMATUIS. Ha realizado proyectos de investigación y extensión en convenio con la Universidad Industrial de Santander, Ministerio de Educación Nacional, Secretaría de Educación Departamental, Secretaría de Educación Municipal. 

Este libro surgió de la necesidad de profundizar en las principales líneas de conocimiento abiertas por el Proyecto Institucional de Uso de la Geometría Dinámica, desarrollado a escala nacional con el fin de establecer el impacto de las tecnologías en la enseñanza de las matemáticas en educación secundaria.

En respuesta a las debilidades encontradas, el grupo de investigación Edumat-UIS formuló el Proyecto Institucional de Uso de la Geometría Dinámica que aborda, entre varios aspectos, las necesidades de formación de los profesores de matemáticas en cuanto al conocimiento de nuevas estrategias de enseñanza, diseño de materiales y nuevas relaciones de trabajo entre el profesor y su propia práctica docente.

Con este documento se dan los primeros pasos para el desarrollo de un currículo de geometría basado en el uso del software de geometría dinámica, se formula un marco teórico que permite diseñar actividades didácticas para alcanzar objetivos de aprendizaje específicos, y analizar y evaluar su implementación en situaciones reales de clase para alumnos de grados sexto, séptimo, octavo y noveno. Por otro lado, la presente publicación abre el camino para incorporar las tecnologías digitales en la enseñanza de las matemáticas de manera asertiva y, además, resulta una estrategia de formación continua para docentes de matemáticas.
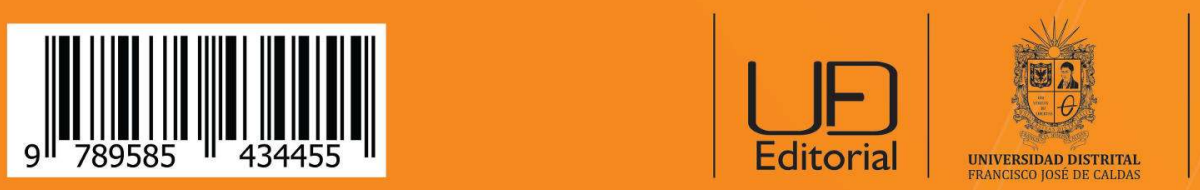